\title{
Parametric study of the dynamic motions and mechanical characteristics of power cables for wave energy converters
}

\author{
Shun-Han Yang $^{1}$ (1) $\cdot$ Jonas W. Ringsberg $^{1} \cdot$ Erland Johnson $^{1,2}$
}

Received: 28 April 2016/Accepted: 12 April 2017/Published online: 28 April 2017

(C) The Author(s) 2017. This article is an open access publication

\begin{abstract}
A case study of a point-absorber wave energy converter (WEC) system is presented. The WEC system forms an array, with several WECs located around a central hub to which they are each connected by a short, freehanging power cable. The objective of the study is to analyse the dynamic characteristics and estimate the fatigue life of the power cable which is not yet in use or available on the commercial market. Hence, a novel approach is adopted in the study considering that the power cable's length is restricted by several factors (e.g., the clearances between the service vessel and seabed and the cable), and the cable is subject to motion and loading from the WEC and to environmental loads from waves and currents (i.e., dynamic cable). The power cable's characteristics are assessed using a numerical model subjected to a parametric analysis, in which the environmental parameters and the cable's design parameters are varied. The results of the numerical simulations are compared and discussed regarding the responses of the power cables, including dynamic motion, curvature, cross-sectional forces, and accumulated fatigue damage. The effects of environmental conditions on the long-term mechanical life spans of the power cables are also investigated. Important cable design parameters that result in a long power cable (fatigue) service life are identified, and the cable service life is predicted. This study contributes a methodology for
\end{abstract}

Shun-Han Yang

Shunhan.Yang@chalmers.se

1 Department of Mechanics and Maritime Sciences, Chalmers University of Technology, SE-412 96 Gothenburg, Sweden

2 Department of Safety-Mechanics Research, SP Technical Research Institute of Sweden, P.O. Box 857, SE-501 15 Borås, Sweden the first-principle design of WEC cables that enables the prediction of cable fatigue life by considering environmental conditions and variations in cable design parameters.

Keywords Cable dynamics $\cdot$ Fatigue $\cdot$ Power cable - Wave energy converter

\section{Introduction}

Recent research by Folley and Whittaker [1] has shown that wave energy converters (WECs) should be grouped into an array around a centrally shared hub for economic viability. The energy produced by the WECs is collected by the hub via power cables and then transmitted ashore. Given the ocean environment in which WECs operate, the cables are affected by other system components and environmental loads, such as the motions of the WEC, motions of the hub, wave loads, and currents. These factors result in dynamic motions along the cable that influences its structural integrity and service life. A reliable cable design is imperative for the cost-effective operation of WEC array systems; however, it is challenging to design and select appropriate cable properties because relevant field experience is lacking [2].

Several issues related to the structural safety of a cable of this type regarding its operational limits have been presented in the literature. First, the cable interior may undergo fretting fatigue damage, which is a major factor that contributes to internal component failure and, in the worst case, the breakage of the entire cable [3, 4]. Second, the complexity of the cable's umbilical geometry can make it difficult to accurately predict the axial stiffness and bending stiffness of the cable. In addition, a realistic 
analysis of cable characteristics must consider a variety of environmental conditions, including currents and waves [5]. Third, variations in the environmental loads, including currents and waves, result in cable fatigue damage. Moreover, because the cable is linked to a floating unit, the interactions between the components and their motions must be considered when evaluating the cable's fatigue damage [2, 4]. Finally, because the target operational service life of a WEC system is generally 25 years, all of the components in the WEC system, including the cable, should be capable of withstanding ageing $[6,7]$.

Underwater power cables are used in several applications. Lane et al. [8] developed a customized procedure capable of reflecting the nonlinear influences of the available materials and manufacturing procedures for flexible risers. In addition, Olsen et al. [9] developed a friction testing device that is capable of determining the friction coefficients between all components in an umbilical riser. To investigate the mobility of a remotely operated vehicle, Katsui et al. [10] developed a numerical method for evaluating cable tension that includes the bending elasticity of the cable. From a motion perspective, Fortaleza et al. [11] investigated the dynamic behaviours of cables used to connect vessel and sea floor equipment during equipment installation, and Aranha and Pinto [12] presented an algebraic approximation for calculating the dynamic tension on submerged lines induced by harmonic motion.

Major progress in the development of power cables has been made since the beginning of the twenty-first century. Karlsen [13] performed tests to measure tension and bending responses to investigate the failure mechanisms of power cables, Green et al. [14] evaluated the cost and performance of cables and illustrated how they are affected by the layout of an offshore wind farm, and Buitrago et al. [15] developed a method for testing the fatigue damage of entire cables. Regarding the umbilical cross section of a cable, Silva et al. [16] studied the viability of using the finite element (FE) method to calculate its allowable bending radius and crush resistance, and Barbeiro and Yamada da Silveira [5] performed a global analysis of the force and stress responses of cables to investigate their axial stiffness.

Research on cables specifically used in marine energy systems has been presented by Thies et al. [2], who developed a numerical approach for assessing the mechanical loading and fatigue life of cables. Marta et al. [17] reviewed different approaches for designing, modelling and testing dynamic power cables that are used in floating offshore renewable energy applications. They found that best practices in the design of "novel" dynamic power cables require performing a global load analysis, with combined hydrodynamic and mechanical modelling, along with both static and dynamic mechanical tests.
Trarieux et al. [18] presented valuable data on the curvature of cables under certain environmental conditions and assessed the causes of potential structural damage to a cable. In their study, the cables were used to monitor systems in the petroleum industry. However, similar measurements are not currently available for the cables that are used in floating WECs; therefore, loading analyses are often based on tank tests and/or numerical model simulations [19].

For a power cable connected to a floating unit (such as the floating WEC discussed in the present study), its fatigue life has been emphasized as a critical engineering challenge in many of the abovementioned studies [2, 4, 13, 15, 17, 19]. Additional studies have also addressed the same issue: Nasution et al. [20-22] conducted a series of experiments and FE analyses to study the fatigue life of copper power conductors. Their research provided insight into the failure mechanisms of power conductors, and the fatigue properties of the conductors were presented in S-N diagrams. Through accelerated reliability tests, Thies et al. [23] investigated the fatigue life of a pipe bend restrictor, which is used to protect static submarine power cables used in offshore wind applications. Hansen-Zahl et al. [24] found that the static configuration of umbilicals and risers has a marked impact on their vortex-induced vibrations. In a configuration with a larger curvature, higher modes are excited, resulting in a shorter fatigue life.

This study investigates a new type of power cable that will be used in an array of point-absorber-type WECs. Compared with the cables that have been presented in the literature, the power cable investigated here is unique in the sense that it is relatively short (less than $100 \mathrm{~m}$ ), has a high degree of flexibility (i.e., a low bending stiffness), and is designed to hang freely in the seawater rather than being in contact with the seabed. Because no similar cable has been presented in the literature for WEC applications, this study contributes to knowledge regarding the design of this type of power cable and its mechanical characteristics. With the aim of assisting in the future development of free-hanging cables for WECs, this study was conducted with two main objectives. First, to develop a methodology (Sect. 2) which enables the evaluation of the cable dynamics (Sect. 4.1) and fatigue life (Sect. 4.3) against its actual environmental conditions and loads (waves and currents). Second, to identify cable design parameters that contribute to reducing the fatigue damage to the cable (Sect. 4.2), and then propose a cable configuration that has a longer fatigue life compared with that of the initial configuration (Sect. 4.3). The main contribution of this study is the establishment of an analysis procedure that enables fatigue-life estimation for a free-hanging power cable used in WEC systems.

The paper is structured as follows. Section 2 presents the developed simulation procedure and the software used 
to investigate the cable's dynamics and fatigue life. The case study WEC system is presented in Sect. 3. The cable properties from an initial design based on preliminary engineering judgement are presented in Sect. 3.3; and a final and improved cable configuration is proposed as an outcome of this study. Results of the study are presented and discussed in Sect. 4. Section 4.1 elaborates on the dynamic cable characteristics under various environmental loads. Based on a parametric study, Sect. 4.2 compares different cable design parameters with regard to the dynamic response of the cable. A demonstration of the fatigue analysis methodology and an evaluation of the cable fatigue life are presented in Sect. 4.3. A new and improved power cable configuration, enhanced with fatigue life as the main objective function, is also presented in Sect. 4.3. Finally, Sect. 5 presents the observations and conclusions drawn from the investigation.

\section{Methodology}

In this study, numerical simulations are introduced to calculate the motion response of an entire WEC system unit within an array (see [2, 17] for a motivation for WEC unit analysis), and a fatigue methodology is developed for the fatigue damage analysis of a power cable attached to the unit. The following sections provide a brief introduction to the simulation procedure and software used.

\subsection{Motion and structural response analysis}

The purpose of the motion and structural response analyses is to investigate the dynamic response of the power cable under operational-mode conditions. The dynamics of a WEC system can be simulated and analysed using both coupled and de-coupled models. In the de-coupled model, a simulation is carried out in two subsequential steps. First, the motion responses of the WEC are calculated in a linear frequencydomain analysis. The motion responses at the fairleads of the mooring lines and the connection point of the cable are postprocessed and transferred to the time-domain. Second, in the following nonlinear time-domain simulations, the responses in the mooring lines and the cable are calculated based on the previously calculated motion responses at the attachment point as prescribed boundary conditions [25, 26]. In the coupled model, the equations of motion of the WEC, the mooring lines, and the cable are simultaneously solved using a nonlinear time-domain analysis. Consequently, the motions of the mooring lines and cable implicitly influence the instantaneous mean position and dynamic response of the WEC [27, 28]. More accurate predictions are expected using the coupled model. Several types of simulation models and various software tools have been investigated in previous studies [29, 30]. From these investigations, it was concluded that the coupled simulation model should be used to analyse the structural responses of the moorings or cables in a WEC system. Hence, the coupled analysis model was used in this study.

The DNV DeepC [31] software was used to determine the motions of the WEC system and the structural responses of the cable. The coupled analysis required two solvers that were incorporated in DeepC: SIMO [32] was used to simulate the motions of the hub and the WEC buoy, and RIFLEX [33] was used to perform the hydrodynamic and structural analyses of the cable and mooring lines. The structural responses of the cable were used as inputs for the fatigue damage analysis (see Sect. 2.2). Specifically, we used the curvatures, cross-sectional axial force, and bending moments determined from the structural responses simulated by DeepC. Based on these results, the stress components of the cable were calculated separately (see Sect. 3.3 for details). Eventually, the total stress history was derived for use in the fatigue damage analysis.

\subsection{Fatigue damage analysis}

The purpose of the fatigue damage analysis is to identify fatigue-critical locations along the length of the cable and to estimate the cable's fatigue life and its dependence on its design and environmental parameters. Hence, the fatigue analysis was performed on a "global" model level according to first-principle design, and the intrinsic failure mechanisms of the cable and their physics were not considered in the model [17]. A detailed design based on the first-principle design presented in this paper should include, e.g., the influences of the wear, fretting, thermal effects, and physical model of the cable, to achieve more realistic fatigue lives. These phenomena and effects will be investigated in future studies.

The cross section of the cable was simplified to a thickwalled tube, see Sect. 3.3 for details. In the numerical model, the cable was modelled using beam elements with constant cross sections. Each cross section was assessed for its weakest fatigue location by calculating the accumulated fatigue damage at 12 points on the periphery of the thickwalled tube, i.e., at the locations separated by an angle of $30^{\circ}$. Thus, the fatigue analysis results can be used to identify fatigue-critical locations associated with variations in the cable characteristics and environmental conditions.

Before obtaining a complete set of numerical simulations, initial test cases were considered to study the stress responses of the cable. These simulations showed that the stress level of the cable is considerably lower than the design yield stress of the current cable design. The stressbased approach was therefore adopted in the fatigue analysis. 
For the fatigue analysis, the stress history of the cable was obtained from time-domain simulations (see Sect. 2.1). In this study, only tensile stresses were assumed to contribute to the fatigue damage in the fatigue analysis; hence, the recorded negative (compressive) stresses were set as zero prior to the cycle counting procedure. Next, the rainflow-counting (RFC) method was used to extract the stress cycles and their corresponding stress ranges from the stress history for the fatigue analysis [34, 35]. The accumulated fatigue damage (FD) was calculated using the Palmgren-Miner cumulative rule and the S-N (stressnumber of cycles to failure) curve for the cable material under consideration as follows:

$\mathrm{FD}=\sum_{i} \frac{n_{i} S_{i}^{m}}{\alpha}$

where $n_{i}$ is the number of stress cycles with the stress range $S_{i}$, which is calculated using the RFC method, and $\alpha$ and $m$ are material parameters in the S-N diagram, which were set to $6.098 \times 10^{19}$ and 6.238 , respectively, in this study [22]. No fatigue limit was considered; thus, all of the stress ranges contributed to the total fatigue damage. The fatigue damage analysis was performed using an in-house code developed in MATLAB [36].

\section{Case study of the WEC system}

Figure 1 shows the WEC array system considered in this investigation, which is currently a candidate for full-scale testing. The WEC array system consists of 8-10 WECs

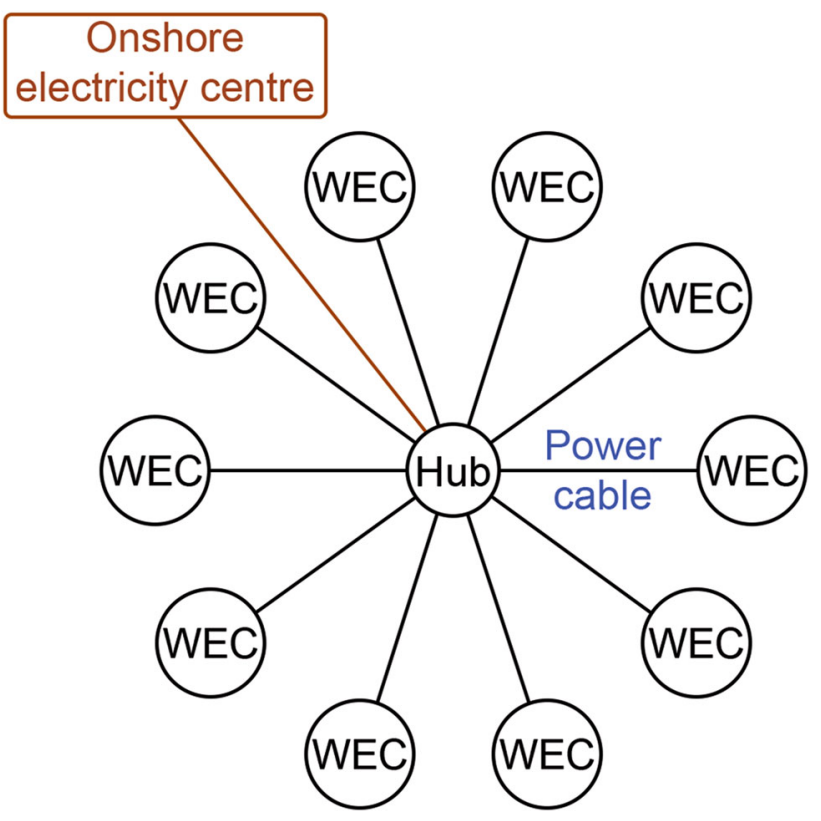

Fig. 1 Schematic of a WEC array system with a central power-gathering hub that collects and transmits the generated electricity to the shore. The connection between a WEC and the hub requires a short power cable (less than $100 \mathrm{~m}$ ); these cables are the focus of this study.

The hub is designed to remain in a static position in the water, which implies that the connection point between a cable and the hub can be considered to be a spatially fixed point. Hence, no interactions or couplings arise between the WECs through the hub's motions, and our case study model can be simplified to a single pair consisting of a WEC and hub connected by a cable. According to the environmental data from our potential test site near Runde, Norway, the WEC array system is expected to be exposed to external environmental loads induced by currents, waves, and winds. However, wind loads are excluded from the present investigation because of a lack of wind measurement data at the actual test site as well as the detailed design of the WEC buoy above the surface of the water; see Sect. 4.3 for a discussion of the influence of this decision on the estimated fatigue life of the cable. By using a parametric study in which the current and wave directions are varied, we can ensure that our case study model is representative of any of the WECs in the WEC array system.

Figure 2 shows the initial configuration of the simplified system. The WEC is composed of a WEC buoy and its positioning mooring system. The origin of our reference Cartesian coordinate system is placed at the water plane at the geometric centre of the WEC buoy when the buoy is subjected to still-water conditions. The WEC buoy floats in a water volume that is infinite in the horizontal $x$ and $y$ directions and is finite in the $z$ direction (see Fig. 2). Under still-water conditions, the WEC buoy is positioned $54 \mathrm{~m}$ horizontally from the fixed hub. In the following sections, the physical and numerical models of the WEC array system and its various components will be described along with the environmental loading conditions.

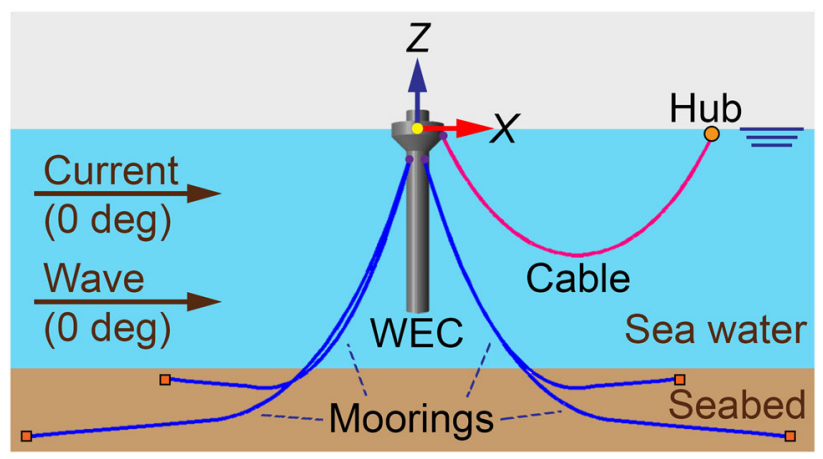

Fig. 2 Illustration of the case study WEC system, including the WEC and its moorings, the hub, the cable, and the definitions of the coordinate axes 


\subsection{WEC}

The WEC is composed of a WEC buoy and its mooring system, which is used for positioning. The WEC buoy is a point absorber developed by the company Waves4Power [37] and generates power from the movement of water inside the tube at its centre. In this study, the numerical model of the WEC buoy was simplified with the assistance of the manufacturer. Figure 3 and Table 1 present the geometric characteristics of the WEC buoy, which is modelled as a closed buoy. The total modelled mass corresponds to the mass of the buoy plus the mass of the water inside the tube under still-water conditions. According to the initial design, water is accelerated in the central tube (the region enclosed by the dashed line). A Morison model was used to capture the viscous drag and transverse drag damping effects from the tube. Constant damping of the heave degree of freedom (DOF) was introduced to incorporate a linear power take-off (PTO) in the model for power production [38]. Note that the WEC model is only representative for the wave heights that define the operational-mode conditions for the current prototype WEC system. It is not yet intended for use in simulating and analysing extreme loading and survival-mode conditions, which are currently defined to correspond to wave heights greater than $8 \mathrm{~m}$. For larger wave heights, the description of the PTO model is still under development.

A catenary mooring system with four moorings, which was first introduced based on a configuration suitable for a point absorber WEC under strong heave and pitch motions $[26,29]$, is considered in this study. The mooring lines are symmetrically attached around the outer rim of the WEC buoy (fairleads on the WEC buoy) and are located at coordinates of $(1.24,1.24,-5.00 \mathrm{~m}),(-1.24,1.24$, $-5.00 \mathrm{~m}),(-1.24,-1.24,-5.00 \mathrm{~m})$ and $(1.24,-1.24$, $-5.00 \mathrm{~m}$ ). The moorings (chain mooring lines) are anchored to the seabed at a horizontal distance of $77.58 \mathrm{~m}$ from the fairleads on the WEC and at a depth of $50 \mathrm{~m}$ under water. The boundary conditions at the anchor point of each mooring line are fixed in all six DOFs at the seabed level, whereas the connection to the WEC fairleads follows its three translational DOFs but allows for free rotation.

Table 1 Properties of the WEC buoy

\begin{tabular}{ll}
\hline Draft, $T(\mathrm{~m})$ & 27.8 \\
Centre of buoyancy $(\mathrm{COB})(x, y, z)(\mathrm{m})$ & $(0,0,-10.9)$ \\
Mass, $M_{\mathrm{WEC}}($ metric tonnes $)$ & 353.8 \\
Centre of gravity $(\mathrm{COG})(x, y, z)(\mathrm{m})$ & $(0,0,-11.8)$ \\
PTO damping in heave DOF, $B_{\text {PTO }}(\mathrm{kNs} / \mathrm{m})$ & 197.1 \\
\hline
\end{tabular}

Fig. 3 (Left) Illustration of the full hydrodynamic model of the WEC; (middle) the geometry of the WEC buoy, where the dashed region represents the tube and $80 \%$ of the tube is filled with water under stillwater conditions (units: $\mathrm{m}$ ); and (right) the geometry of the Morison model used to evaluate the viscous drag damping effect from the motion of water (units: m)

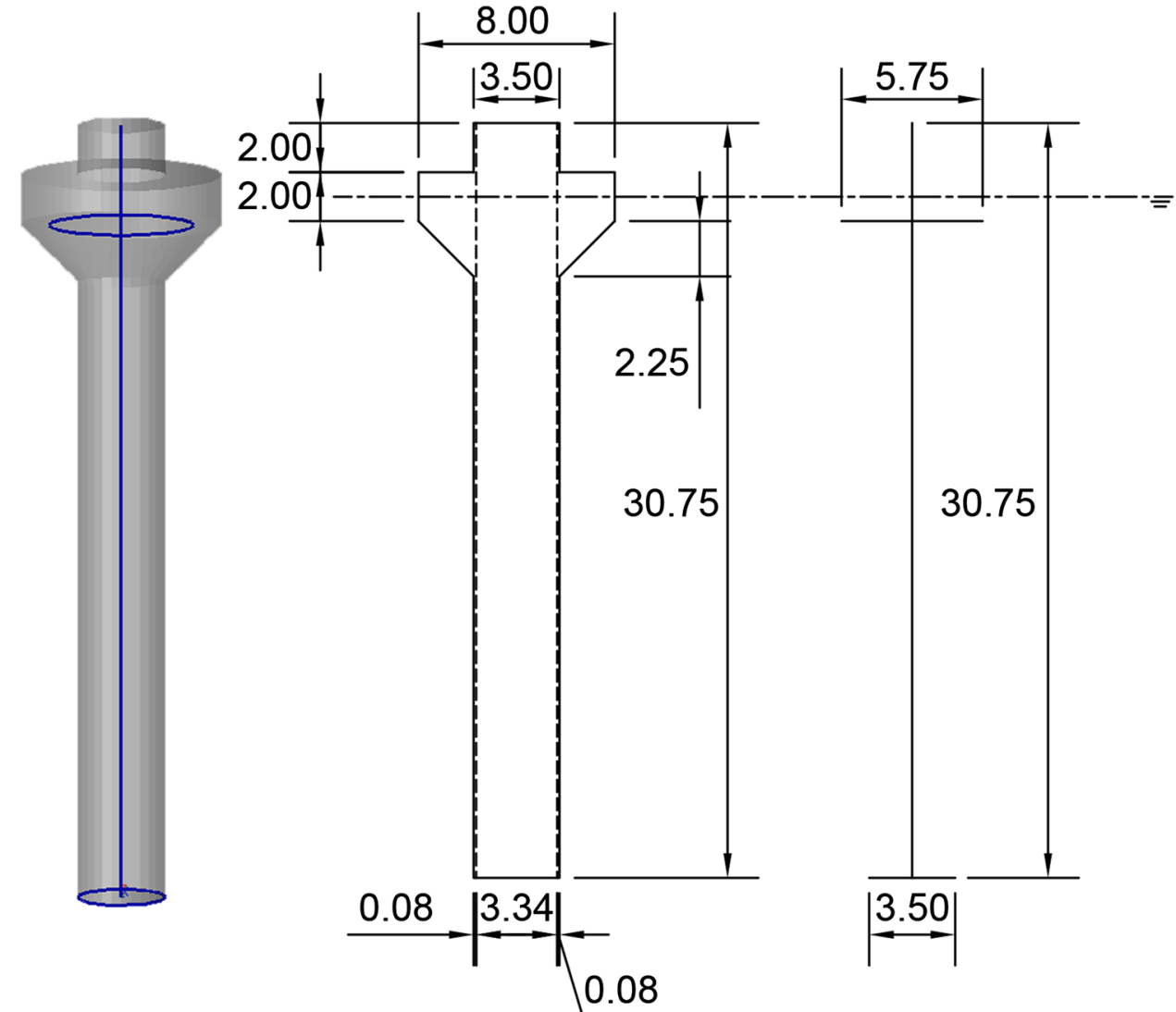


Table 2 Properties of the mooring lines

\begin{tabular}{ll}
\hline Length, $L_{\mathrm{M}}(\mathrm{m})$ & 100.0 \\
Nominal diameter, $d_{\mathrm{MN}}(\mathrm{m})$ & 0.048 \\
Effective diameter for hydrodynamic analysis, $d_{\mathrm{ME}}(\mathrm{m})$ & 0.086 \\
Axial stiffness, $E A_{\mathrm{M}}(\mathrm{MN})$ & 193 \\
Mass, $M_{\mathrm{M}}(\mathrm{kg} / \mathrm{m})$ & 45.0 \\
Normal flow added mass coefficient, $C_{\mathrm{MnM}}(-)$ & 3.8 \\
Normal flow drag coefficient, $C_{\mathrm{DnM}}(-)$ & 2.5 \\
Tangential flow drag coefficient, $C_{\mathrm{DtM}}(-)$ & 0.5 \\
Structural damping coefficient, $\beta_{\mathrm{M}}(-)$ & 0.025 \\
\hline
\end{tabular}

The geometry, stiffnesses, and mass data (see Table 2) were obtained using the Orcina [39] design tool for chain moorings. The hydrodynamic and structural responses of the mooring lines were solved using element discretization and the FE method. Other details regarding the FE model parameters and its applicability can be found in previous studies [29, 30].

\subsection{Hub}

The hub of the WEC array system is a cylinder that is rigid with respect to the seabed, which prevents movement and ensures that the position of the hub remains fixed. In this investigation, the hub was assumed to remain stationary at point $(x, y, z)=(54.0,0.0,-1.0 \mathrm{~m})$, namely, its centre of buoyancy.

\subsection{Cable}

Power cables used in similar applications have umbilical cross sections [2, 4, 40]. However, during the investigations presented herein, a new cable was being developed as an initial design, and a new and "improved" design is proposed as a result of the current study. The power cable model was simplified from one with an umbilical cross section to a circular tube with a small inner diameter. This simplification relies on the assumption that the mechanical strength of the cable is provided by its armouring layer [41]. Therefore, the current model is not able to account for damage caused by wear or fretting, and the prediction of the mechanical fatigue life will be overestimated as a result. Table 3 presents the cable properties according to the initial design. In the simulation software, the cable was modelled using two-node beam elements with six DOFs for each node (three translations and three rotations) [42]. During deformation, the cross sections remain planar, according to Euler-Bernoulli theory [42]. Three hydrodynamic coefficients $\left(C_{\mathrm{MnC}}, C_{\mathrm{DnC}}\right.$, and $\left.C_{\mathrm{DtC}}\right)$ were chosen in accordance with the suggested design values from [43], whereas the Rayleigh damping coefficient was obtained from [44].
Table 3 Reference values for the cable properties according to the initial design

\begin{tabular}{ll}
\hline Length, $L_{\mathrm{C}}(\mathrm{m})$ & 70.0 \\
Outer diameter, $d_{\text {out }}(\mathrm{m})$ & 0.040 \\
Inner diameter, $d_{\text {in }}(\mathrm{m})$ & 0.020 \\
Axial stiffness, $E A_{\mathrm{C}}(\mathrm{kN})$ & 94.3 \\
Bending stiffness, $E I_{\mathrm{C}}\left(\mathrm{Nm}^{2}\right)$ & 350.0 \\
Torsional stiffness, $G K_{\mathrm{C}}\left(\mathrm{Nm}^{2} / \mathrm{rad}\right)$ & 7.85 \\
Mass, $M_{\mathrm{C}}(\mathrm{kg} / \mathrm{m})$ & 2.75 \\
Submerged weight, $W_{\mathrm{C}}(\mathrm{N})$ & 1000.6 \\
Normal flow added mass coefficient, $C_{\mathrm{MnC}}(-)$ & 1.0 \\
Normal flow drag coefficient, $C_{\mathrm{DnC}}(-)$ & 1.2 \\
Tangential flow drag coefficient, $C_{\mathrm{DtC}}(-)$ & 0.0 \\
Structural damping coefficient, $\beta_{\mathrm{C}}(-)$ & 0.025 \\
\hline
\end{tabular}

The distribution of elements along the length of the cable is uniform. A convergence analysis shows that calculations of the motion and stress along the cable are insensitive to element sizes of less than $0.7 \mathrm{~m}$. Consequently, an element size of $0.7 \mathrm{~m}$ was selected as the standard mesh size for the cable.

The cable is defined in terms of a curvilinear coordinate system, wherein the $s$ coordinate is a coordinate running along the length of the cable, with a value of 0 at the connection point to the WEC and a maximum value at the connection point to the hub. In addition, the $y_{c}$ axis is the average direction of the principal $y$ axes at the two ends; and the $z_{c}$ axis is perpendicular to the $s-y_{c}$ plane. For each cross section, we consider the outermost edge to be the most critical area for the stress response and we calculate the stress and fatigue responses in several points on the periphery for comparison (see Sect. 2.2). Therefore, the stress for the different peripheral points in the cable at position $s$, denoted by $\sigma_{s}$, is calculated as follows:

$$
\begin{aligned}
\sigma_{s}= & \frac{N_{s}(s)}{A} \\
& +\frac{M_{y c}(s) \cdot\left(d_{\text {out }} / 2\right) \cdot \sin (\theta)-M_{z c}(s) \cdot\left(d_{\text {out }} / 2\right) \cdot \cos (\theta)}{I}
\end{aligned}
$$

$A=\frac{\pi}{4}\left(d_{\text {out }}^{2}-d_{\text {in }}^{2}\right) ; I=\frac{\pi}{64}\left(d_{\text {out }}^{4}-d_{\text {in }}^{4}\right)$

where $N_{s}$ is the axial force at the cross section at $s ; M_{y c}$ and $M_{z c}$ are the corresponding bending moments in the $y_{c}$ and $z_{c}$ directions at $s$, respectively; $\theta$ is an angle in the $y_{c}-z_{c}$ plane (defined as zero along the $y_{c}$ axis, increments of $30^{\circ}$ are used in the analyses); and $A$ and $I$ are the cross-sectional area and second moment of area around the cable, respectively.

The cable is connected to the hub and WEC, and because the hub is assumed to be stationary, the end node of the cable connected to the hub is modelled as fixed (with 
neither translations nor rotations). The end node of the cable follows the WEC in all six DOFs.

The boundary conditions near the hub and WEC will influence the responses of the cable near these positions. At this time, the detailed design of these connections is not finalized; therefore, the investigation of all results starts at $1.4 \mathrm{~m}$ from the end, with the first two elements removed from both ends of the cable to exclude any uncertainties in the cable characteristics induced by the modelling of the boundary conditions. These joints will be investigated more thoroughly in future studies to determine whether they will represent weak links in the system with respect to fatigue.

\subsection{Sea water}

Sea water is modelled as an incompressible, inviscid, and irrotational fluid. Thus, the theory of sea water dynamics is based on potential flow, and the velocity components of sea water are uniquely determined by the gradient of the harmonic velocity potential. Although the water is assumed to be inviscid, a nonzero kinematic viscosity was introduced to model the viscous drag effect of the water on the cable and moorings and in the Morison model of the WEC. Additional descriptions of sea water can be found in $[42,45]$. Table 4 presents the sea water properties used in the numerical model.

\subsection{Wave}

Regular waves were considered in this study to determine the dynamic behaviour of the cable under different wave conditions. Furthermore, restrictions were introduced under the assumption of small wave amplitudes and Airy wave theory $[42,45]$. A regular wave is defined by its direction, height, and period. In this study, these parameters were systematically varied to study their effects (see Sect. 4.1.2 for details).

\subsection{Current}

The capability of the power cable to resist ocean currents is emphasized as one of the key criteria for its design. Therefore, a current generated by wind and tides was

Table 4 Sea water properties

\begin{tabular}{ll}
\hline Acceleration of gravity, $g\left(\mathrm{~m} / \mathrm{s}^{2}\right)$ & 9.81 \\
Density, $\rho_{\mathrm{w}}\left(\mathrm{kg} / \mathrm{m}^{3}\right)$ & 1025.0 \\
Kinematic viscosity, $\mu\left(\mathrm{m} / \mathrm{s}^{2}\right)$ & $1.19 \times 10^{-6}$ \\
Still-water mean level, $Z(\mathrm{~m})$ & 0.0 \\
Water depth, $h(\mathrm{~m})$ & 50.0 \\
\hline
\end{tabular}

considered. The WEC development company Waves4Power [37] has performed ocean current measurements at the test site. For this study, they provided a design value for the current speed, which was set to $1.0 \mathrm{~m} / \mathrm{s}$. The vertical current profile was estimated as described in [43]. The current direction was varied as an independent variable in the parametric investigation (see Sect. 4.1.2).

\subsection{Seabed}

The seabed is modelled as a horizontal plane with an elastic normal stiffness of 1.0 MPa and a tangential friction coefficient of 1.0. The normal stiffness is modelled as a linear force-displacement relationship with no damping [42]. In the case of mooring-seabed contact, the friction force is calculated as the tangential friction coefficient multiplied by the normal force that acts on the mooring from the mooring-seabed contact.

\subsection{Model of the contact between the cable and the WEC}

Section 3.7 describes the model of the contact between the moorings and seabed. Other types of contacts may also be relevant, such as the contact between the cable and the WEC buoy. The software used in this study did not include a model of the contact between the cable and the WEC buoy. Thus, if such a contact were to occur, post-processing of the results would show the cable penetrating through the WEC buoy. Because of the absence of a contact model between the cable and the WEC, this type of contact has no influence on the results of the motion and structural response analyses of the WEC system (see details in Sect. 4.1.1).

\subsection{Solution method and numerical parameters}

The equation of motion for the assembled FE model of the WEC system can be written as follows [45]:

$M \ddot{\boldsymbol{x}}+D \dot{\boldsymbol{x}}+K \boldsymbol{x}+\int_{0}^{t} h(t-\tau) \dot{\boldsymbol{x}}(\tau) \mathrm{d} \tau=\boldsymbol{q}(t, \boldsymbol{x}, \dot{\boldsymbol{x}})$

where $\ddot{\boldsymbol{x}}, \dot{\boldsymbol{x}}$ and $\boldsymbol{x}$ represent the acceleration, velocity and displacement vectors of the system, respectively; the matrices $M, D$ and $K$ represent the mass of the system (including the ordinary mass and added mass contributions), the damping and the stiffness; and $h(\tau)$ is the retardation function computed by a transform of the frequency-dependent added-mass and damping. The vector $\boldsymbol{q}(t, \boldsymbol{x}, \dot{\boldsymbol{x}})$ represents the wave excitation forces, drag force, and any other forces, such as wave drift damping. In the coupled simulation procedure, the response vectors $(\ddot{\boldsymbol{x}}, \dot{\boldsymbol{x}}$ and $\boldsymbol{x}$ ) in Eq. 4 consist of six DOFs from the WEC and 
additional DOFs from the mooring system and the cable. The dynamic equilibrium of the system is solved using the Newmark- $\beta$ time stepping scheme. The relationships between the displacement, velocity and acceleration vectors at times $t$ and $t+\Delta t$ are as follows:

$\dot{\boldsymbol{x}}_{t+\Delta t}=\dot{\boldsymbol{x}}_{t}+(1-\gamma) \ddot{\boldsymbol{x}}_{t} \Delta t+\gamma \ddot{\boldsymbol{x}}_{t+\Delta t} \Delta t$

$\boldsymbol{x}_{t+\Delta t}=\boldsymbol{x}_{t}+\dot{\boldsymbol{x}}_{t} \Delta t+\left(\frac{1}{2}-\beta\right) \ddot{\boldsymbol{x}}_{t}(\Delta t)^{2}+\beta \ddot{\boldsymbol{x}}_{t+\Delta t}(\Delta t)^{2}$

where $\gamma$ and $\beta$ are parameters that affect the behaviours of the time steps, such as accuracy, stability, numerical dispersion and dissipation. The Newmark parameters $\gamma$ and $\beta$ were chosen as $1 / 2$ and $1 / 4$, respectively [42, 45]. A time step of $2 \times 10^{-3} \mathrm{~s}$ was used in all simulations to capture the cable and mooring dynamics (see [29, 30] for details).

Because of significant nonlinearities in the cable and mooring system, it is important to perform this type of simulation in the time domain [46-49]. The motions of all components instantaneously influence the mean positions and dynamic responses of all other components. Because these coupling effects are captured in the analysis, more accurate predictions are expected.

\section{Results and discussion}

\subsection{Dynamic responses of the cable under environmental loads}

This chapter presents the results for the dynamic responses of the cable under the actual environmental conditions and loads at its expected site of operation. The cable's characteristics are assessed based on the initial cable design (see Sect. 3.3 for details). Section 4.1.1 focuses on the instantaneous motion response of the cable, and subsequently, a parametric sensitivity study of environmental loads is presented in Sect. 4.1.2.

\subsubsection{Instantaneous dynamic behaviour of the cable}

The motion and structural responses of the cable and WEC were simulated under various wave and current conditions. The implications of the different variables were animated for ease of observation; the animation snapshots (as presented in Fig. 4) offer additional insight compared with plain numerical readings. Two particular phenomena can be observed. First, the motion of the cable and WEC may cause instantaneous contact between the cable and WEC (Fig. 4a). Because of the lack of an appropriate contact model (see Sect. 3.8), this observation can be made only through post-processing of the results. Second, in addition to the overall bending of the cable, wave propagation causes additional local bending and rippling along the cable (Fig. 4b).

According to the Specification 17E standard of the American Petroleum Institute (API) [50], several failure criteria must be assessed during the design of a power cable. As shown in Fig. 4a, compression (negative axial stress values) can occur in parts of the cable, potentially leading to bird-caging failure [50]. However, the initial investigation showed that this phenomenon is minor. Another failure criterion related to the allowable bending radius (ABR) [50] is derived from the curvature of the cable; therefore, to determine whether the ABR condition is met, the curvature of the cable must be calculated. Furthermore, the curvature determines the corresponding bending stress response of the cable and controls the fatigue damage to the cable along with the axial stress, as shown in Eqs. 1 and 2. Considering the umbilical cross section of the practical cable model, the curvature of the cable also leads to internal motion and friction between internal umbilicals, which results in additional internal damage [16]. Thus, we selected curvature as the principal evaluation parameter when investigating the influences of the various loadings and design parameters.

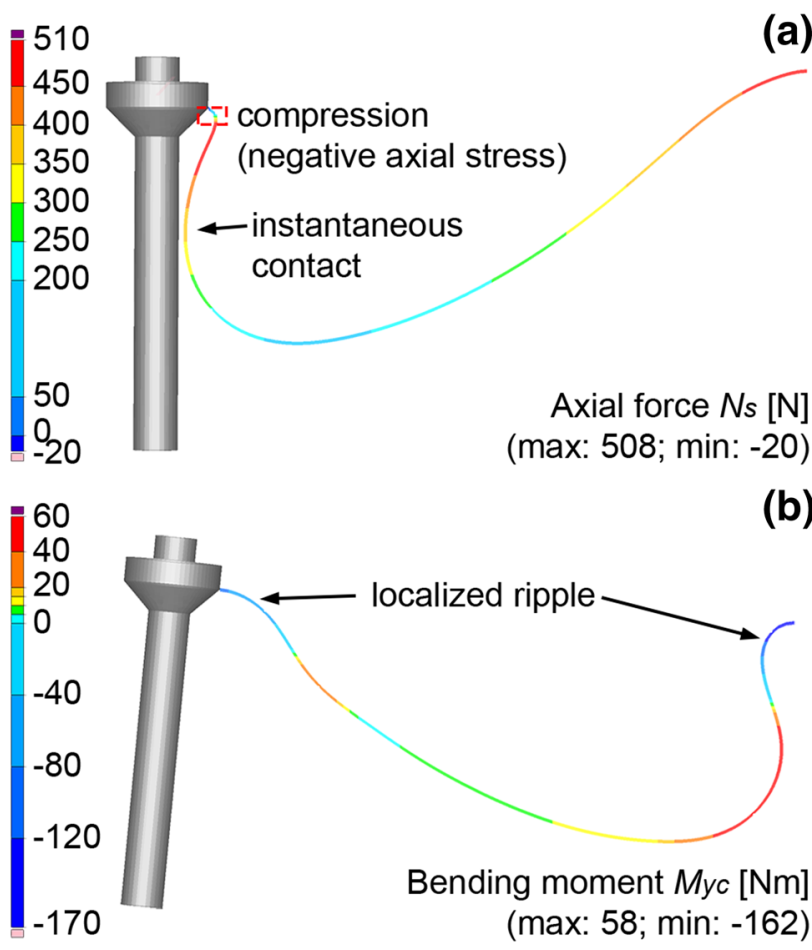

Fig. 4 Animation snapshots from the motion and structural response analysis: a contact between the cable and WEC (current direction of $180^{\circ}$, wave direction of $0^{\circ}$, wave height of $3.5 \mathrm{~m}$, and wave period of $7.5 \mathrm{~s}$ ), and $\mathbf{b}$ a localized ripple along the cable (current direction of $0^{\circ}$, wave direction of $0^{\circ}$, wave height of $6.5 \mathrm{~m}$, and wave period of $10.5 \mathrm{~s})$ 


\subsubsection{Investigation of the dynamic characteristics of the cable under environmental loads}

Although a WEC system is generally designed to operate in a particular marine environment, the environmental loading conditions are continuously changing. Because different environmental loads (such as loads from waves and currents) result in different dynamic responses in the system, the behaviour of the WEC system (and, hence, the cable) must be investigated over a range of environmental loading parameters. Table 5 presents the range of values considered for each parameter that describe the loads from waves and currents. The ranges of the wave height and period were chosen based on the prevailing conditions, namely, the wave scatter diagram acquired at the test site, which is presented in Table 6. To maintain the energy content of the wave when studying the fatigue damage of the cable, each wave condition in the DeepC software is simulated as a regular wave represented by the mean wave height, $H=H_{s} / \sqrt{2}$, and average wave period, $T=T_{z}$. With a reference diameter of $8 \mathrm{~m}$, the Reynolds numbers for all investigated cases were between $2.95 \times 10^{5}$ and $2.18 \times 10^{7}[43]$.

The wave scatter diagram was provided by Waves4Power [37]. All weather conditions with no probability of occurrence (cells with a value of 0 ) were excluded from the simulations. Because of the limitations of linear wave theory (Sect. 3.5), it was necessary to place restrictions on the wave steepness parameter and the shallow water parameter to avoid invalid results from the numerical simulations [43, 51]. All possible weather conditions were divided into three categories: the white cells lie in the valid range for linear wave theory, the light grey cells lie in the intermediate range between linear wave theory and other nonlinear wave theories, and the dark grey cells would require higher-order nonlinear theories in the simulations. In this study, the weather conditions represented by the white and light grey cells were simulated (all cells within the dashed region in Table 6).

Although the conditions represented by the dark grey cells were excluded from the simulations, it is worth noting that most of the dark grey cells coincide with the survival conditions of the WEC system (see Sect. 3.1). Linear Airy

Table 5 Variations in the environmental loads

\begin{tabular}{ll}
\hline Environmental load & Studied cases \\
\hline Current $(-)$ & Yes/no \\
Current direction $\left(^{\circ}\right)$ & $0,90,180,270$ \\
Wave direction $\left(^{\circ}\right)$ & $0,90,180,270$ \\
Wave height, $H_{s}(\mathrm{~m})$ & $0.5-7.5$ in intervals of $1 \mathrm{~m}$ \\
Wave period, $T_{z}(\mathrm{~s})$ & $3.5-15.5$ in intervals of $1 \mathrm{~s}$ \\
\hline
\end{tabular}

wave theory is therefore demonstrated to be sufficient for studying the cable's dynamics under conditions in which the system is in its operational mode. Together, the simulated cases cover $72.8 \%$ of all possible wave load cases at the planned test site and $74.4 \%$ of all possible operationalmode conditions.

Originally, a duration of $30 \mathrm{~min}$ was simulated. The results showed that after an initial transient phase (after 15 min of simulation time), the structural response of the cable reaches stable conditions, and a periodic result can be observed throughout the remainder of the simulation. To avoid transient start-up effects in the comparison and to reduce the total computation time, a time interval of $10 \mathrm{~min}$, from 900 to $1500 \mathrm{~s}$, was considered in the subsequent investigations.

4.1.2.1 Currents Figure 5 presents examples of the results obtained by varying the current, where the horizontal axis represents the line coordinate along the cable $(s)$ and the vertical axis shows the curvature observed during $10 \mathrm{~min}$ of the stable simulation results. The curvature $\kappa_{z}$ was generally minor compared with $\kappa_{y}$ in all but two simulations. One of these examples is shown in Fig. 5a, where, for a current at $90^{\circ}$ (the other case is at $270^{\circ}$ due to symmetry), the curvatures $\kappa_{y}$ and $\kappa_{z}$ are comparable in magnitude along the length of the cable. In Fig. 5b, the vertical axis shows the absolute value of the maximum curvature $\left(\kappa_{y}\right)$ observed during $10 \mathrm{~min}$ of the stable simulation results for some current directions. In addition, the cable curvature under static conditions, representing the installation conditions, was found to be negligible compared with the dynamic response of the curvature; thus, the curvature induced by the cable's static position is less than $5 \%$ of the curvature of any instantaneous dynamic motion. Therefore, the maximum curvature $\kappa_{y}$ was plotted in Fig. $5 \mathrm{~b}$ to determine the most critical response during the motion of the cable.

Note that the WEC system is symmetrical with respect to the $x$ axis, meaning that the results for currents at $90^{\circ}$ and $270^{\circ}$ are identical. In addition, when the current is perpendicular to the cable $\left(90^{\circ}\right.$ and $\left.270^{\circ}\right)$, a low curvature response is observed. Because these observations are valid for most other wave conditions (there are some exceptions, but their probabilities in the scatter diagram are low), currents at $90^{\circ}$ and $270^{\circ}$ are considered to represent the mild current conditions for our WEC system.

As mentioned in Sect. 3.3, the first two elements at both ends of the cable are neglected in the plot; however, the results still show that the most critical area lies near one of the end points of the cable (Fig. 5). Moreover, the most critical area is located near the WEC in most cases, although under a few weather conditions, the most critical area may also occur near the hub (as in the curvature 
Table 6 Wave scatter diagram at the test site (unit: $1 \times 10^{-5}$ )

\begin{tabular}{|c|c|c|c|c|c|c|c|c|c|c|c|c|c|c|c|}
\hline \multirow{2}{*}{$H_{s}[\mathrm{~m}]$} & \multicolumn{14}{|c|}{$T_{z}[\mathrm{~s}]$} & \multirow{2}{*}{ Sum } \\
\hline & 2.5 & 3.5 & 4.5 & 5.5 & 6.5 & 7.5 & 8.5 & 9.5 & 10.5 & 11.5 & 12.5 & 13.5 & 14.5 & 15.5 & \\
\hline 12.5 & 0 & 0 & 0 & 0 & 0 & 0 & 0 & 1 & 2 & 3 & 0 & 0 & 0 & 0 & 6 \\
\hline 11.5 & 0 & 0 & 0 & 0 & 0 & 0 & 0 & 2 & 7 & 0 & 0 & 0 & 0 & 0 & 9 \\
\hline 10.5 & 0 & 0 & 0 & 0 & 0 & 0 & 0 & 11 & 10 & 0 & 0 & 0 & 0 & 0 & 21 \\
\hline 9.5 & 0 & 0 & 0 & 0 & 0 & 0 & 6 & 42 & 10 & 0 & 0 & 0 & 0 & 0 & 58 \\
\hline 8.5 & 0 & 0 & 0 & 0 & 0 & 2 & 29 & 87 & 2 & 0 & 0 & 0 & 0 & 0 & 120 \\
\hline 7.5 & 0 & 0 & 0 & 0 & 0 & 14 & 107 & 103 & 2 & 0 & 0 & 0 & 0 & 0 & 226 \\
\hline 6.5 & 0 & 0 & 0 & 0 & 0 & 44 & 267 & 33 & 5 & 1 & 0 & 0 & 0 & 0 & 350 \\
\hline 5.5 & 0 & 0 & 0 & 0 & 7 & 166 & 337 & 37 & 7 & 2 & 0 & 1 & 0 & 0 & 557 \\
\hline 4.5 & 0 & 0 & 0 & 0 & 43 & 558 & 136 & 32 & 14 & 5 & 1 & 1 & 0 & 0 & 790 \\
\hline 3.5 & 0 & 0 & 0 & 1 & 371 & 563 & 123 & 48 & 19 & 6 & 2 & 1 & 0 & 0 & 1134 \\
\hline 2.5 & 0 & 0 & 4 & 179 & 877 & 303 & 130 & 71 & 33 & 16 & 7 & 2 & 0 & 0 & 1622 \\
\hline 1.5 & 0 & 0 & 221 & 1014 & 501 & 220 & 146 & 110 & 66 & 36 & 16 & 3 & 1 & 0 & 2334 \\
\hline 0.5 & 644 & 367 & 684 & 248 & 107 & 142 & 162 & 192 & 117 & 64 & 19 & 22 & 3 & 4 & 2775 \\
\hline Sum & 644 & 367 & 909 & 1442 & 1906 & 2012 & 1443 & 769 & 294 & 133 & 45 & 30 & 4 & 4 & 10002 \\
\hline
\end{tabular}

response for a $0^{\circ}$ current shown in Fig. 5). Given the significant change in curvature per unit length near the two ends of the cable, the decision to use the third element from the WEC end of the cable to represent the results for the different simulation cases appears to be well motivated (see the discussion regarding the modelling of the boundary condition in Sect. 3.3).

4.1.2.2 Waves Given a particular wave height and wave period, Fig. 6 shows one example of the maximum curvature responses $\kappa_{y}$ and $\kappa_{z}$ of the third element of the cable near the WEC versus the current direction and wave direction (note that $\kappa_{y}$ is larger than $\kappa_{z}$ in all but two cases). The figure shows the capacity of the methodology presented in this investigation and provides an overview of how different combinations of wave loads and current directions influenced the curvature responses of the cable. The information presented, together with the data from the real environmental conditions where the WEC will be operated, can guide the creation of a structural design that fulfils the requirements and expected functionality. At the test site considered in this investigation, a current is always present. Hence, the cable must be designed based on numerical simulations in which a current is included. According to Fig. 6a and b, the worst case corresponds to a current angled at $180^{\circ}$ and a wave angled at $180^{\circ}$; thus, this scenario was chosen for the investigation of various cable design parameters. In addition, the results show that the curvature response $\kappa_{y}$ is much larger than $\kappa_{z}$. Therefore, $\kappa_{y}$ is used in the presentation of results in the following sections and figures, although the cable characteristics are always evaluated against both $\kappa_{y}$ and $\kappa_{z}$.

The wave height and wave period were also investigated, with the results shown in Fig. 7. One can observe that the peak curvatures occur at a high wave height and a wave period similar to the resonance condition of the WEC buoy (a wave period of $6.25 \mathrm{~s}$ ). This observation is also valid for most other current and wave directions, except at a current direction of $90^{\circ}$ or $270^{\circ}$. When the current is perpendicular to the cable, the maximum curvature is insensitive to the wave period and is influenced only by the wave height. Consequently, a high wave height will always lead to a large curvature response, regardless of the wave period. This observation suggests that the influence of the current and wave directions should also be considered in conjunction with the wave height and wave period when identifying extreme conditions for consideration in a cable design. According to our study, the maximum curvature response of the cable was observed under an environmental condition with a wave height of $7.5 \mathrm{~m}$, a wave period of $10.5 \mathrm{~s}$, and wave and current directions of $180^{\circ}$. The maximum curvature response $\kappa_{y}$ was found to be $1.1 \mathrm{~m}^{-1}$, 
(a)

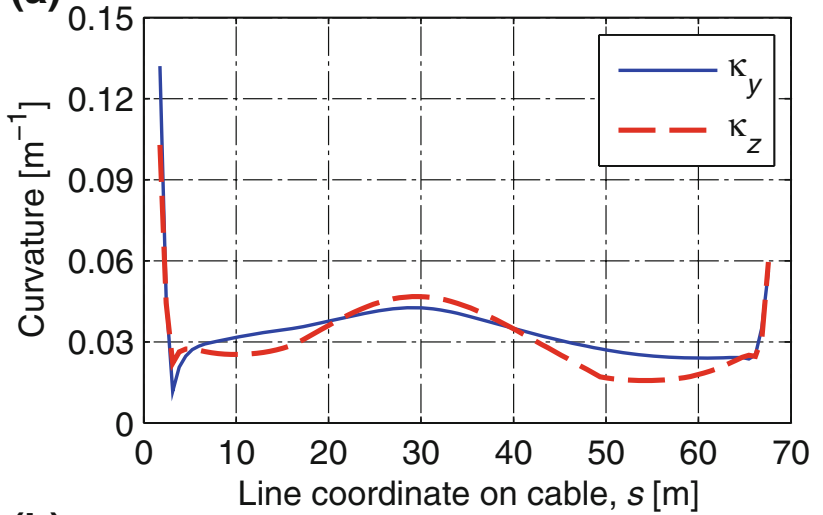

(b)

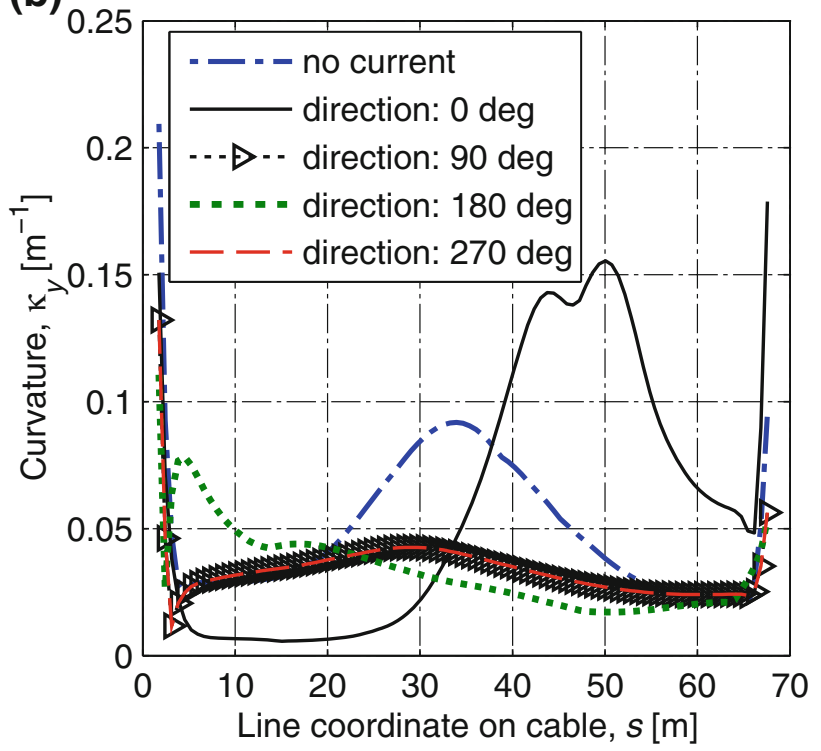

Fig. 5 a Comparison of the absolute values of the maximum curvature responses $\kappa_{y}$ and $\kappa_{z}$ (current direction of $90^{\circ}$, wave direction of $0^{\circ}$, wave height of $7.5 \mathrm{~m}$, and wave period of $10.5 \mathrm{~s}$ ). b Absolute values of the maximum curvature responses $\kappa_{y}$ under different currents (wave direction of $0^{\circ}$, wave height of $7.5 \mathrm{~m}$, and wave period of $10.5 \mathrm{~s}$ )

which is a result of a horizontal shift of the WEC buoy by $18.9 \mathrm{~m}$ and a vertical shift by $3.3 \mathrm{~m}$ from its original position in the still-water condition.

4.1.2.3 Concluding remarks To proceed with the parametric study of the cable design parameters, it was necessary to identify a suitable reference condition in terms of wave and current characteristics. First, the condition chosen for such a purpose should have a high probability of occurrence to ensure that the observed result can be regarded as the typical condition under regular usage. Second, because the intrinsic purpose of the WEC is to harvest energy, the chosen condition should be similar to the resonant wave condition [52]. Finally, this reference condition should not be too mild to avoid the risk of neglecting phenomena that could damage the cable (see Sect. 4.1.1). Accordingly, we chose a reference condition corresponding to a current direction of $180^{\circ}$, a wave direction of $180^{\circ}$, a wave height of $3.5 \mathrm{~m}$, and a wave period of $7.5 \mathrm{~s}$ for further investigation, as presented in the following sections.

\subsection{Parametric study of cable design parameters}

The cable configuration introduced in Sect. 3.3 is the initial design created based on the experience and engineering judgement of the cable manufacturer. However, because of the special cable characteristics required for the application considered here (see Sect. 1 for details), it is necessary to review this initial cable configuration to determine if any improvements can be made with regard to its performance. The structural response of a cable depends on its geometry and material properties. From a global analysis perspective, the main cable properties of interest are the outer diameter, mass, length, axial stiffness, and bending stiffness [5]. In addition, the length and bending stiffness of the cable
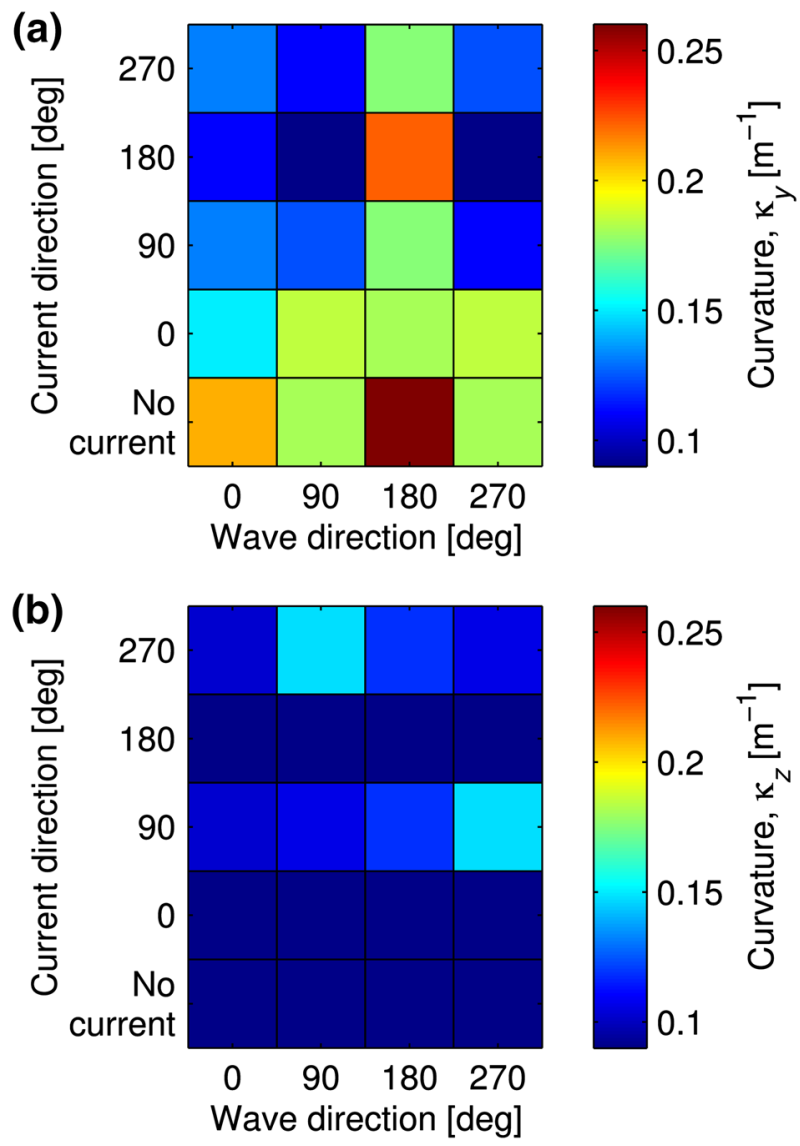

Fig. 6 Absolute value of the maximum curvature response a $\kappa_{y}$ and b $\kappa_{z}$ at the third element of the cable from the WEC for different current and wave directions (wave height of $3.5 \mathrm{~m}$ and wave period of $7.5 \mathrm{~s})$ 
Fig. 7 Absolute value of the maximum curvature response $\kappa_{y}$ at the third element of the cable from the WEC for different wave conditions (current direction of $180^{\circ}$ and wave direction of $180^{\circ}$ ). The invalid and transitional ranges for the application of linear wave theory are indicated by dark grey cells and thick black lines. The light grey and white cells were excluded from the simulations because their probabilities of occurrence are zero. For all wave conditions that were not simulated, the corresponding cells are marked with black dots
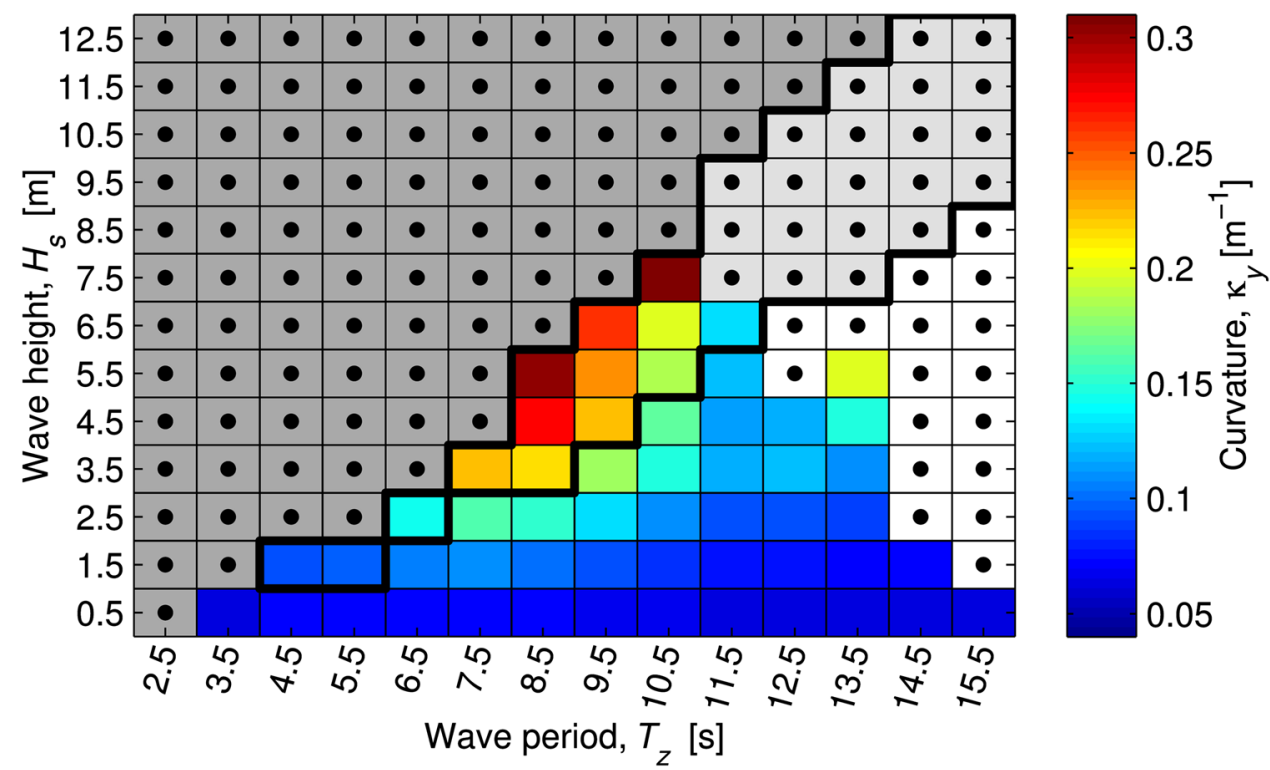

0.1

0.05 require special attention because of the observed risk of contact and localized rippling along the cable, which is addressed in Sect. 4.1.1. Because of these factors, we identify the cable's mass, length, and bending stiffness as key parameters that may be modified to enhance the cable's fatigue life. As each of these parameters is varied in the parametric sensitivity study, all other cable properties are held fixed at the values defined in Sect. 3.3. Table 7 presents all 18 investigated cases, including the variations in the design parameters. These cases were determined to represent realistic parameter values for the current case study configuration. Based on the systems engineering approach [53], the values to be investigated were selected in collaboration with Waves4Power [37] and the cable manufacturer. Note that Case 11 is identical to the initial design of the cable as introduced in Sect. 3.3. The environmental condition used as the basis for the discussion in this section corresponds to a current direction of $180^{\circ}$, a
Table 7 Cable design parameters considered in the parametric study

\begin{tabular}{|c|c|c|c|c|c|c|c|c|}
\hline & \multicolumn{8}{|c|}{ Properties of the cable } \\
\hline & \multicolumn{3}{|c|}{ Mass, $M_{\mathrm{C}}(\mathrm{kg} / \mathrm{m})$} & \multicolumn{3}{|c|}{ Bending stiffness, $E I_{\mathrm{C}}\left(\mathrm{Nm}^{2}\right)$} & \multicolumn{2}{|c|}{ Length, $L_{\mathrm{C}}(\mathrm{m})$} \\
\hline & 2.00 & 2.75 & 6.00 & 50.0 & 200.0 & 350.0 & 70.0 & 82.0 \\
\hline Case 1 & $x$ & & & $x$ & & & $x$ & \\
\hline Case 2 & $x$ & & & $x$ & & & & $\times$ \\
\hline Case 3 & $x$ & & & & $x$ & & $x$ & \\
\hline Case 4 & $x$ & & & & $x$ & & & $x$ \\
\hline Case 5 & $x$ & & & & & $\times$ & $x$ & \\
\hline Case 6 & $x$ & & & & & $x$ & & $\times$ \\
\hline Case 7 & & $\times$ & & $\times$ & & & $\times$ & \\
\hline Case 8 & & $x$ & & $x$ & & & & $x$ \\
\hline Case 9 & & $\times$ & & & $x$ & & $\times$ & \\
\hline Case 10 & & $x$ & & & $x$ & & & $\times$ \\
\hline Case 11 & & $\times$ & & & & $x$ & $x$ & \\
\hline Case 12 & & $\times$ & & & & $x$ & & $\times$ \\
\hline Case 13 & & & $\times$ & $\times$ & & & $x$ & \\
\hline Case 14 & & & $\times$ & $x$ & & & & $\times$ \\
\hline Case 15 & & & $\times$ & & $x$ & & $x$ & \\
\hline Case 16 & & & $\times$ & & $x$ & & & $\times$ \\
\hline Case 17 & & & $\times$ & & & $\times$ & $x$ & \\
\hline Case 18 & & & $x$ & & & $x$ & & $x$ \\
\hline
\end{tabular}


wave direction of $180^{\circ}$, a wave height of $3.5 \mathrm{~m}$, and a wave period of $7.5 \mathrm{~s}$ (see Sect. 4.1.2 for the related discussion).

\subsubsection{Mass of the cable}

The initial mass of the cable $\left(M_{\mathrm{C}}\right)$ was determined based on the internal umbilicals required for electricity transmission (see Table 3). However, because of the observed risk of contact between the cable and the WEC, a greater cable mass was proposed as an alternative to reduce cable movement and mitigate the risk of contact. Waves4Power [37] and the cable manufacturer provided the lower and upper mass limits, which were determined by production limitations.

Figure 8 shows the maximum curvature response along the cable during $10 \mathrm{~min}$ of stable simulations for different cable masses, with a constant bending stiffness of $350 \mathrm{Nm}^{2}$ and a constant length of $70 \mathrm{~m}$ (cases 5, 11, and 17 in Table 7). Figure 8 is consistent with our expectation that a low cable mass is not preferred because a smaller mass introduces more motion and leads to higher peak curvature magnitudes and significant ripples. Since this observation is also valid for other combinations of bending stiffness and length, the use of a higher-mass cable is recommended. However, because heavier cables are typically produced by adding more internal wires, further localized evaluation of the cable cross section is required to reach a final recommendation regarding the cable mass.

\subsubsection{Bending stiffness of the cable}

From a motion perspective, a large bending stiffness may be preferable in order to reduce the motion (and hence the

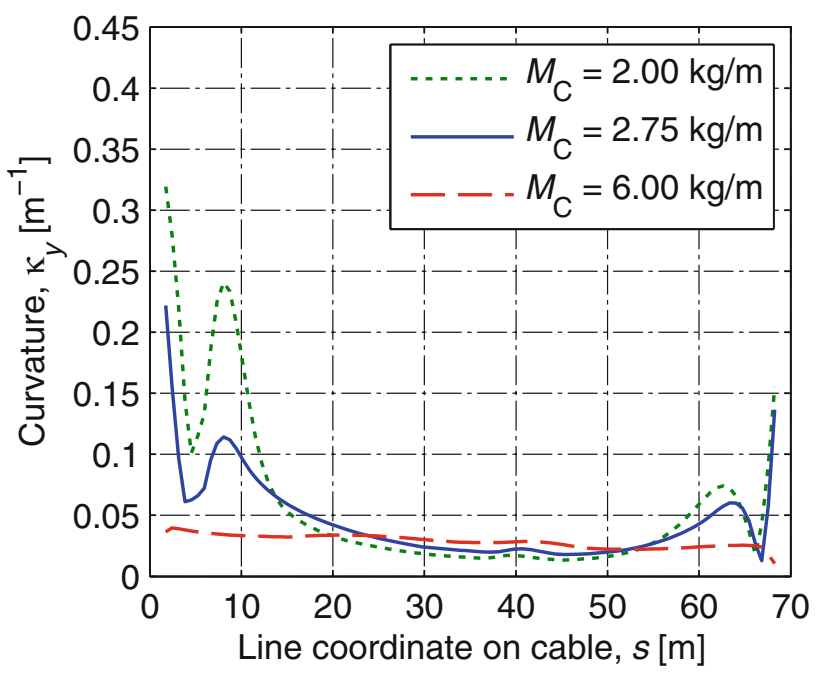

Fig. 8 Absolute value of the maximum curvature responses for different cable masses: $2.00 \mathrm{~kg} / \mathrm{m}$ (case 5 ), $2.75 \mathrm{~kg} / \mathrm{m}$ (case 11), and $6.00 \mathrm{~kg} / \mathrm{m}$ (case 17) (current direction of $180^{\circ}$, wave direction of $180^{\circ}$, wave height of $3.5 \mathrm{~m}$, and wave period of $7.5 \mathrm{~s}$ )
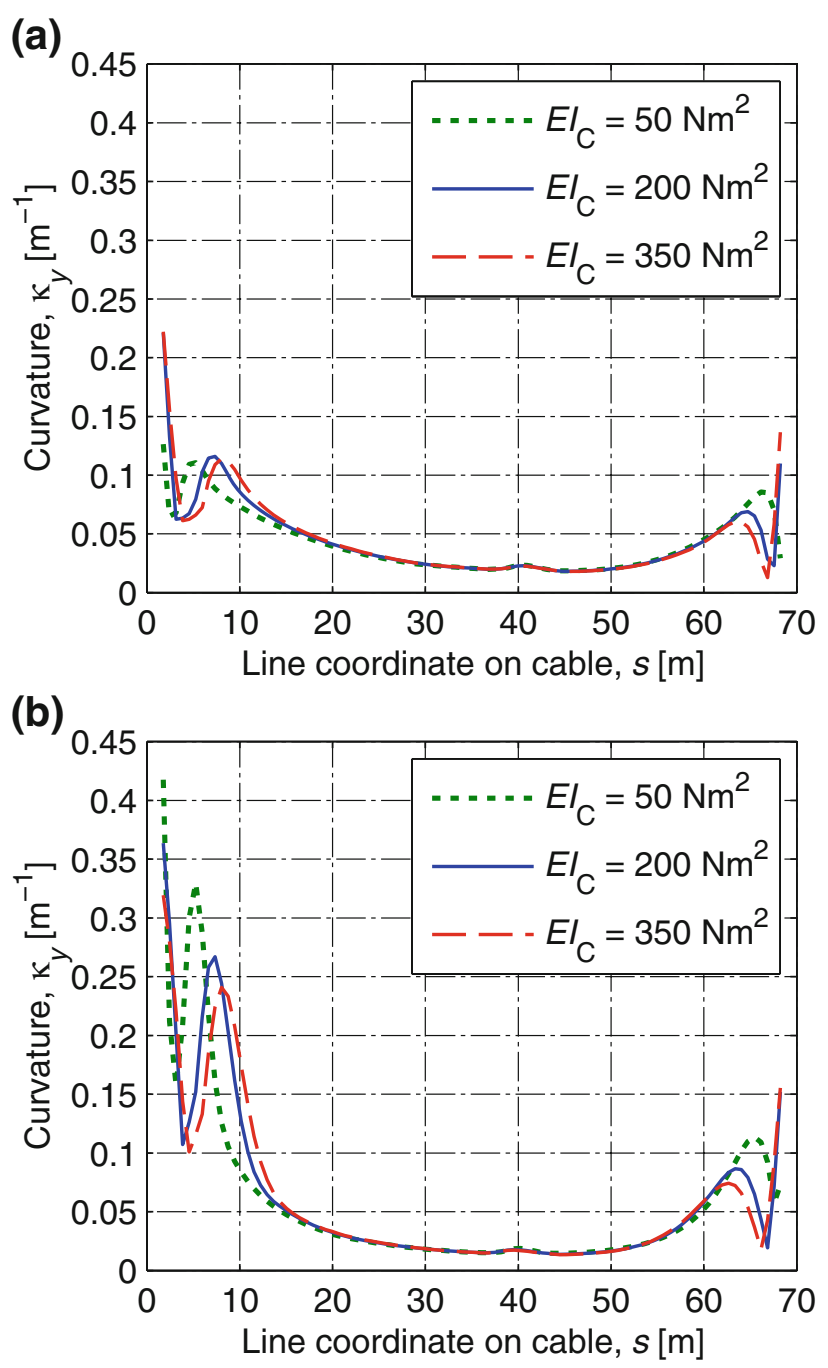

Fig. 9 Absolute value of the maximum curvature responses for different cable bending stiffnesses (current direction of $180^{\circ}$, wave direction of $180^{\circ}$, wave height of $3.5 \mathrm{~m}$, and wave period of $7.5 \mathrm{~s}$ ), cable length $70 \mathrm{~m}$, and cable mass a $2.75 \mathrm{~kg} / \mathrm{m}$ and $\mathbf{b} 2.00 \mathrm{~kg} / \mathrm{m}$

curvature response) of the cable. The bending stiffness was varied to identify a suitable balance point between the curvature and stress responses. The range for investigation was selected based on the properties of the available materials used in cable production.

Figure 9 shows examples of the influences of different bending stiffness values and cable masses on the curvature response. Figure 9a shows that the bending stiffness has only a minor influence on the curvature response for a cable with a mass of $2.75 \mathrm{~kg} / \mathrm{m}$. However, Fig. $9 \mathrm{~b}$ shows that the curvature response close to the WEC is more sensitive to the bending stiffness for a cable mass of $2.00 \mathrm{~kg} / \mathrm{m}$. Furthermore, after reviewing the results for all 18 cases in Table 7, it was found that using a bending stiffness of $200 \mathrm{Nm}^{2}$ is appropriate and that the cable mass is an important design parameter for reducing the curvature 
responses for our WEC system (see Fig. 9). The effects of different bending stiffness values on the stress response will be discussed in Sect. 4.3.

\subsubsection{Length of the cable}

The possible range of the cable length is determined by two counteracting factors. First, the cable cannot be shorter than a given lower bound because of the minimum requirement of the clearance between a service vessel and the cable. Second, the longest length is constrained by the amount of spare cable, which must not touch the seabed. Given these two factors, the possible range for the cable length is between 70 and $82 \mathrm{~m}$, and these two end values were chosen for comparison.

Figure 10 shows examples of the absolute values of the maximum curvature responses of cables with different lengths, bending stiffness, and masses. Figure 10a shows that minor differences in the curvature response occurred between two cables with different lengths and a bending stiffness of $200 \mathrm{Nm}^{2}$ and a cable mass of $2.75 \mathrm{~kg} / \mathrm{m}$. Figure $10 \mathrm{~b}$ shows that the curvature response for the shorter cable will increase near the WEC if the bending stiffness and cable mass are reduced. These results show the importance of carrying out parametric studies to observe and determine which combination of design parameters should be recommended in the early design phase.

Post-processing by animation of the cable motions for the $82 \mathrm{~m}$ cable shows many cases where unwanted contact between the cable and the WEC buoy occurs; this happened only for a few cases for the $70 \mathrm{~m}$ cable. From a structural integrity perspective, such contact is undesirable. Severe contact can result in damage to the cords or indent damage to the cable, thereby negatively influencing its mechanical life. Hence, we chose to maintain a cable length of $70 \mathrm{~m}$.

\subsection{Stress and fatigue damage evaluation}

As described in Sects. 2.2 and 3.3, the stress response and accumulated fatigue damage in the cable at line coordinate $s$ were calculated at 12 locations in the cross sections described by the angular coordinate $\theta$. An assessment of every cross section was used to determine the location and magnitude of the largest accumulated fatigue damage. Figure 11 shows an example of how this assessment was carried out. In Fig. 11a, the variation of the accumulated fatigue damage is shown for 12 locations in a cross section at $s=1.75 \mathrm{~m}$ when only the current direction is altered. From this analysis, Fig. 11b shows how each fatigue-critical cross section location (represented by $\theta$ ) in the cable changes with the length $(s)$ of the cable for some current directions. This example demonstrates the necessity of

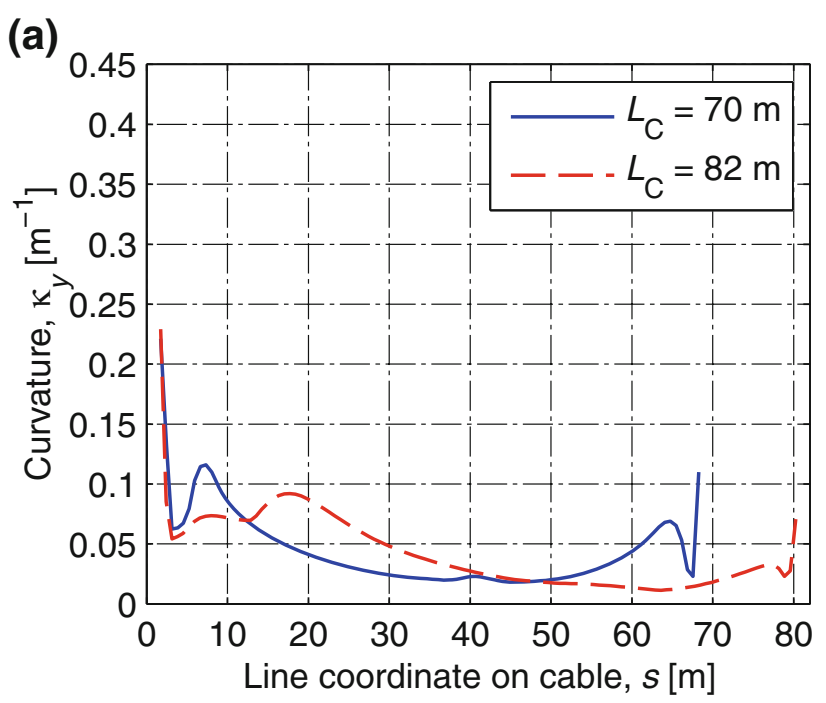

(b)

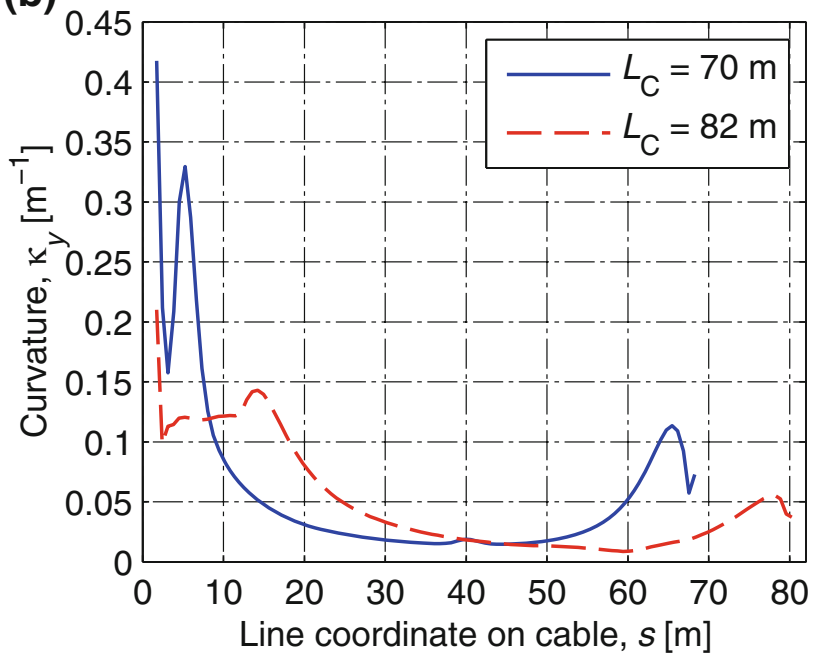

Fig. 10 Absolute value of the maximum curvature responses for different cable lengths (current direction of $180^{\circ}$, wave direction of $180^{\circ}$, wave height of $3.5 \mathrm{~m}$, and wave period of $7.5 \mathrm{~s}$ ): a bending stiffness $200 \mathrm{Nm}^{2}$ and cable mass $2.75 \mathrm{~kg} / \mathrm{m}$, and b bending stiffness $50 \mathrm{Nm}^{2}$ and cable mass $2.00 \mathrm{~kg} / \mathrm{m}$

employing systematic and thorough fatigue assessments at several locations of a cross section.

Figure 12 shows an example of the stress responses corresponding to the three stress terms in Eq. 2 and the total stress at various points along the cable. In this example, the mass was varied as an independent variable, and the bending stiffness and length were held constant at $200 \mathrm{Nm}^{2}$ and $70 \mathrm{~m}$, respectively (cases 3, 9, and 15 in Table 7). The results shown in Fig. 12 and those obtained for other combinations of bending stiffness and length show that, for different cable masses, the contribution from the axial stress to the total stress is either minor $\left(M_{\mathrm{C}}=2.00 \mathrm{~kg} / \mathrm{m}\right)$, meaning that the bending stress is the major source of the total stress, or the axial stress has a 
Fig. 11 Example of the influences of the current direction: a assessment of the accumulated fatigue damage at several locations in a cross section in a line with coordinate $s=1.75$ m (i.e., third element from the WEC), and

b presentation of the most fatigue-critical location of each cross section along the length of the cable (wave direction of $90^{\circ}$, wave height of $3.5 \mathrm{~m}$, and wave period of $7.5 \mathrm{~s}$ )
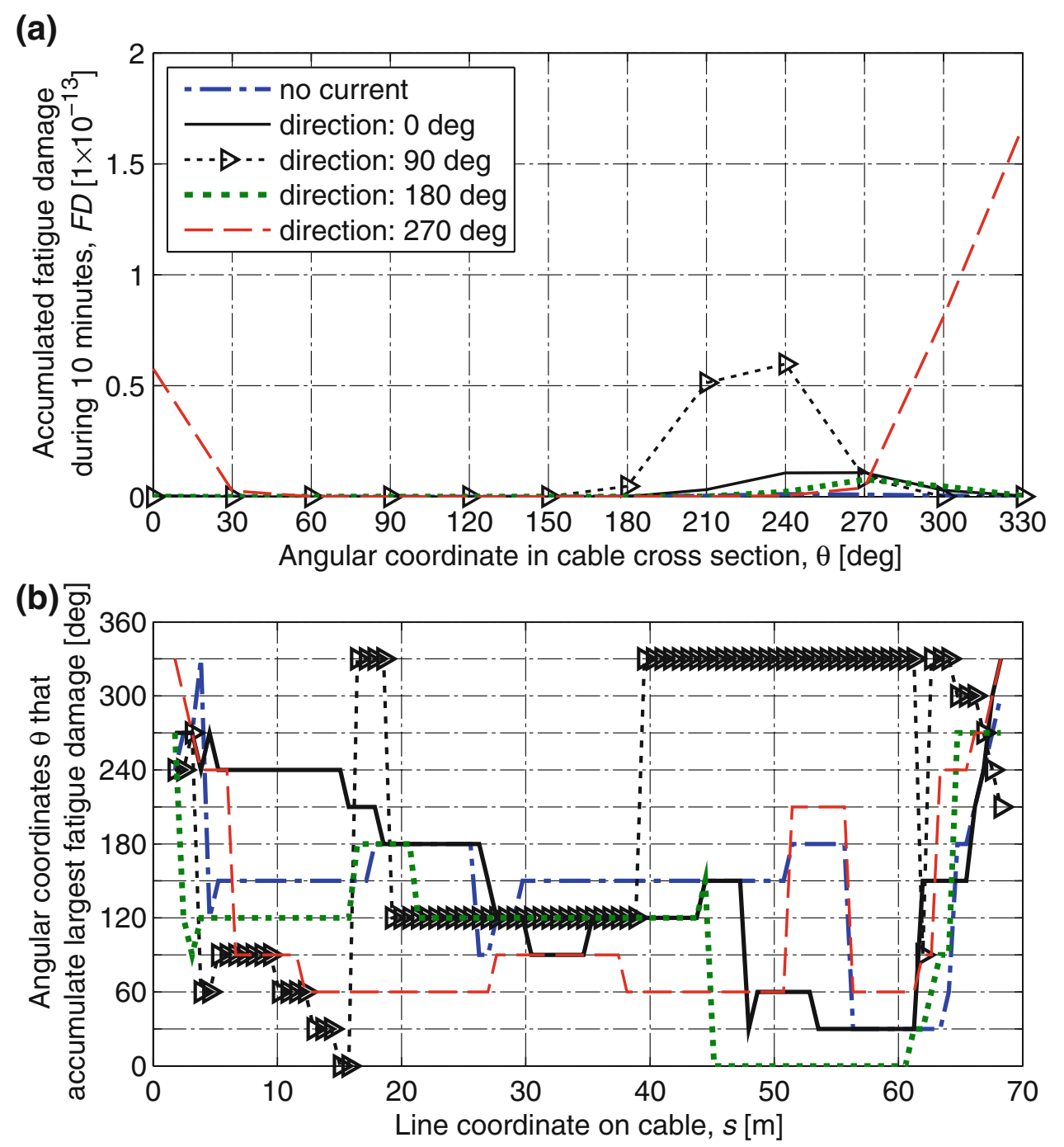

pronounced contribution $\left(M_{\mathrm{C}} \geq 2.75 \mathrm{~kg} / \mathrm{m}\right)$ when the line coordinate $s$ is (approximately) in the interval $5<s<65$.

Figure 13 shows an example of the accumulated fatigue damage values (on the left vertical axis) for different cable masses (the bending stiffness and length were held at $200 \mathrm{Nm}^{2}$ and $70 \mathrm{~m}$, respectively) and bending stiffnesses (the cable mass and length were held at $2.00 \mathrm{~kg} / \mathrm{m}$ and $70 \mathrm{~m}$, respectively). A comparison with Fig. 12, which indicates the critical area for the total stress response, shows that the most critical areas for fatigue damage are expected to be located at the two ends of the cable. The right vertical axis in Fig. 13 presents the equivalent fatigue life corresponding to each value of accumulated fatigue damage.

Together, Figs. 9 and 13 affirm the dilemma encountered when varying both the bending stiffness and cable mass. For example, when the bending stiffness of a cable with low cable mass is increased, the curvature response of the cable decreases (Fig. 9b) but the fatigue damage to the cable increases (Fig. 13b). This result suggests that if a cable is designed for lower motion and curvature response (namely, with a high bending stiffness), the cable will be prone to cyclic tensile stress-induced fatigue damage. However, if the cable is designed to allow for greater motion and curvature responses (with a low bending stiffness), an advanced model must also be used to predict the intrinsic failure mechanisms of the cable, such as wear and fretting damage between the internal cable umbilicals [54]. For our case study WEC system, the "improved" cable design that is recommended among the studied cases is a cable with a mass of $2.00 \mathrm{~kg} / \mathrm{m}$, a bending stiffness of $50 \mathrm{Nm}^{2}$, and a length of $70 \mathrm{~m}$, for the following two reasons: the risk of contact between the cable and the WEC is low (see Sect. 4.2.3), and the fatigue lifetime along the length of the cable is the longest (see Fig. 13b). Under the specific environmental condition represented in Fig. 13, the initial cable and the proposed "improved" cable have fatigue lives of $1.8 \times 10^{6}$ and $6.7 \times 10^{9}$ years, respectively. Notably, if production criteria are limiting and vital for allowable parameter configurations (see Sects. 4.2.1, 
Fig. 12 Maximum a axial stress $\sigma_{\mathrm{A}}, \mathbf{b}$ bending stress $\sigma_{y c}$, $\mathbf{c}$ bending stress $\sigma_{z c}$, and $\mathbf{d}$ total stress $\sigma_{s}$ responses for different cable masses: $2.00 \mathrm{~kg} / \mathrm{m}$ (case 3), $2.75 \mathrm{~kg} / \mathrm{m}$ (case 9), and $6.00 \mathrm{~kg} / \mathrm{m}$ (case 15) (current direction of $180^{\circ}$, wave direction of $180^{\circ}$, wave height of $3.5 \mathrm{~m}$, and wave period of $7.5 \mathrm{~s})$ (a)

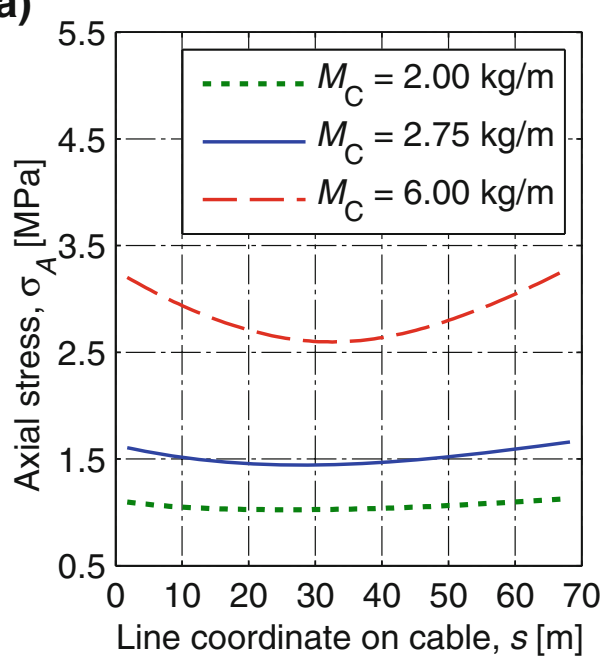

(c)

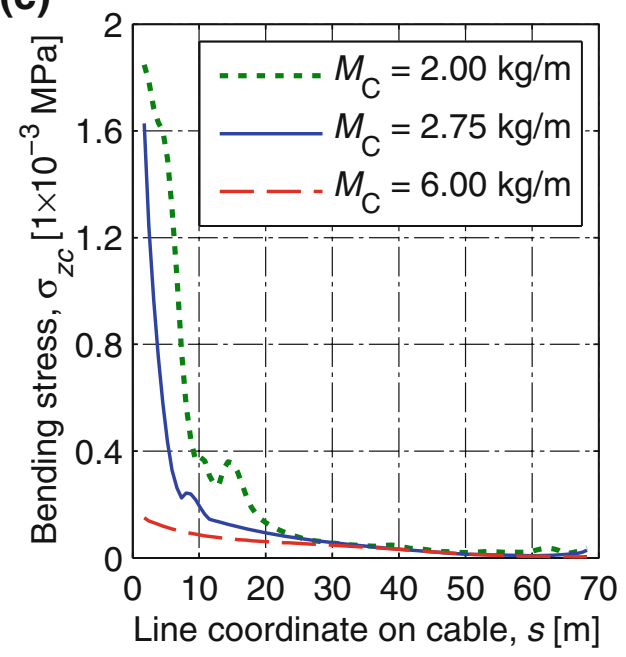

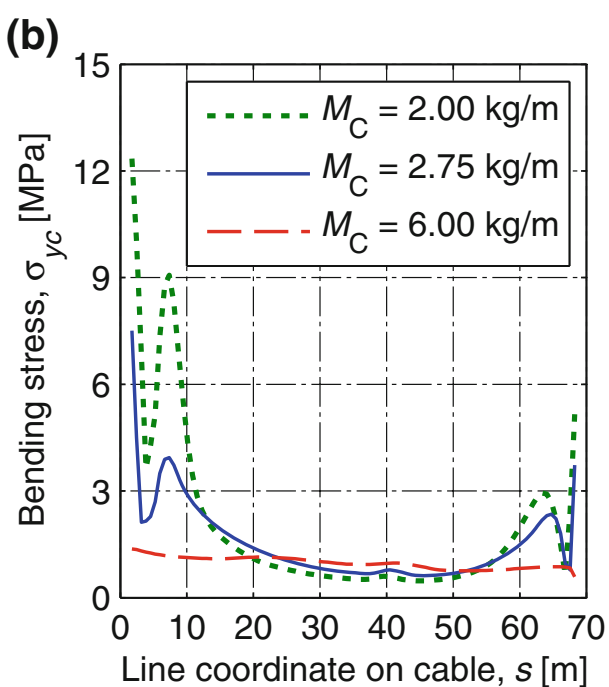

(d)

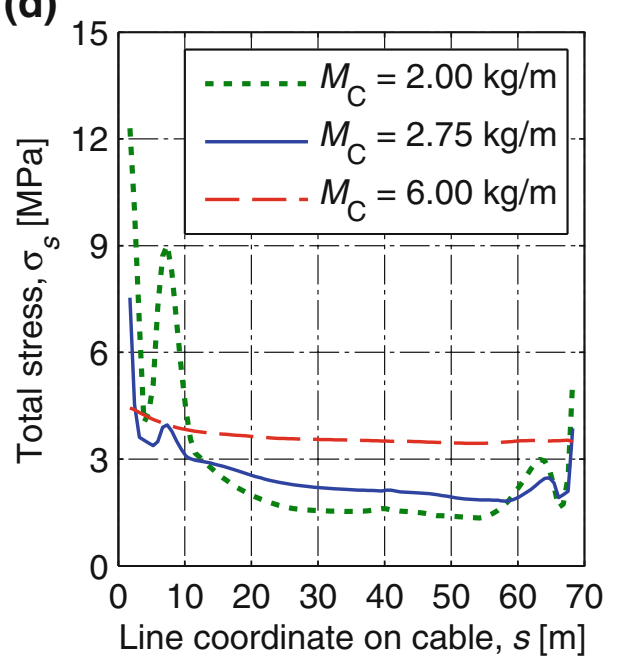

4.2.2), the fatigue life could be significantly lower, especially near the end points.

In practice, bend stiffeners are used at both ends of the cable to protect it from over-bending and buckling; see [23] for an example. At the time this study was conducted, the design of the bend stiffener for the cable was not available. Therefore, it was not included in the cable model. In the post-processing of the results, the first two elements of the cable at both ends (which each corresponds to the length of a bend stiffener) were excluded from the assessment of the numerical results since they cannot represent the (true) boundary conditions properly. The results from the fatigue evaluation, presented in Fig. 13, show that the most fatigue-critical point occurred near the WEC side in the third element of the cable. This simplification to the cable model was studied in a few simulation cases in which a new cable model was used with a preliminary bend stiffener design. When the bend stiffener was modelled, the maximum curvature response of the power cable was reduced by $85 \%$ in the first element near the WEC and by $90 \%$ near the hub.
Nevertheless, the results from these simulations showed that the most fatigue-critical location was in approximately the same location as indicated by the fatigue evaluation presented herein, i.e., at a point at the same distance from the WEC side. A comparison of the calculated fatigue lives showed that they were of the same order of magnitude. Therefore, considering the purpose of the current study, the simplified cable model without bend stiffeners was considered suitable.

As indicated in Sect. 4.1.2, the curvature response of the cable depends on the environmental conditions. One can expect that the service life predicted in a fatigue damage evaluation based on a single environmental condition (such as that shown in Fig. 13) will not be accurate or comprehensive. Thus, to more realistically predict the fatigue life of the cable, we treated the wave height and wave period as independent variables, and assumed a current and wave angles of $180^{\circ}$. A "fatigue-wave height-wave period" matrix was computed, which shows the cable fatigue damage under different wave conditions; see Fig. 14. 

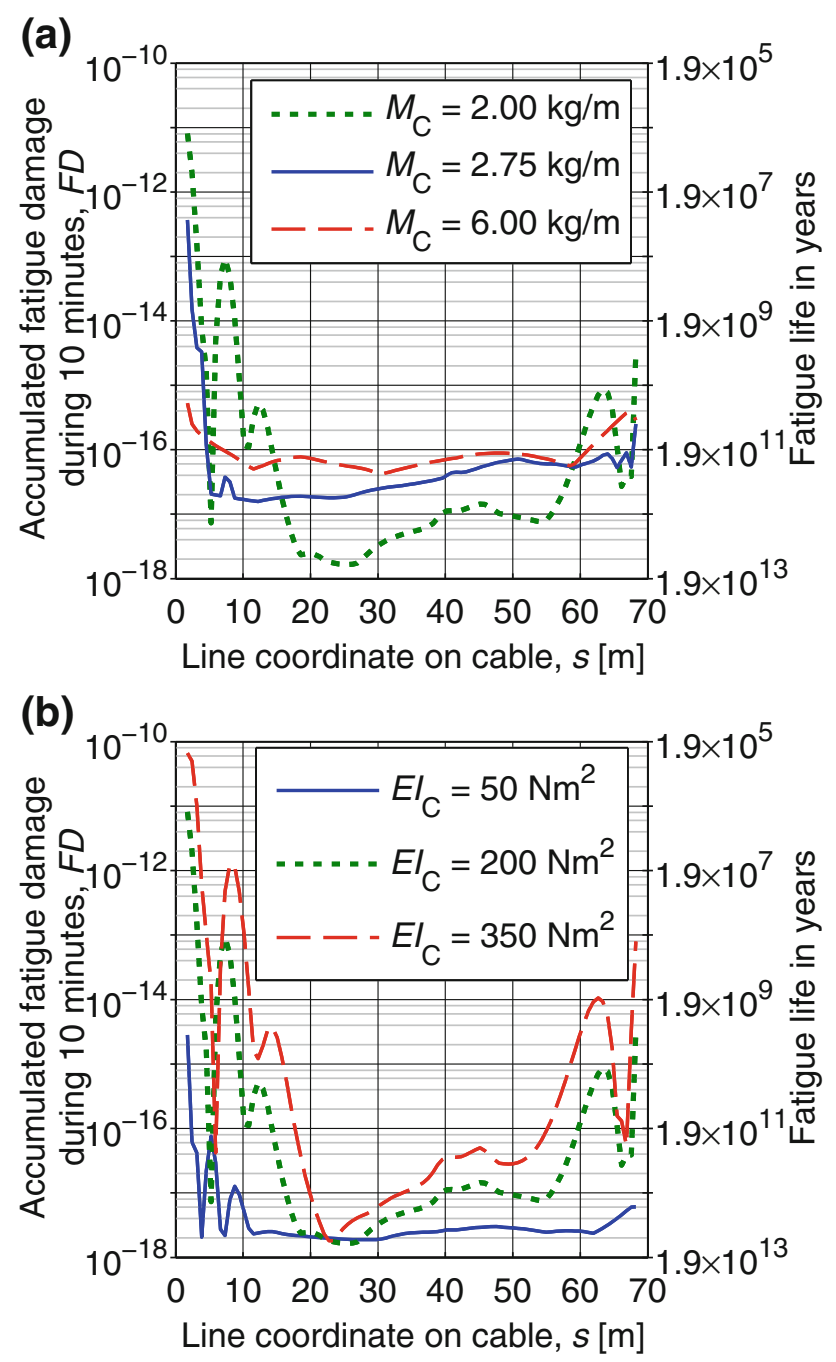

Fig. 13 Accumulated fatigue damage during $10 \mathrm{~min}$ of stable response a for different cable masses: $2.00 \mathrm{~kg} / \mathrm{m}$ (case 3), $2.75 \mathrm{~kg} / \mathrm{m}$ (case 9), and $6.00 \mathrm{~kg} / \mathrm{m}$ (case 15) b for different cable bending stiffnesses: $50 \mathrm{Nm}^{2}$ (case 1), $200 \mathrm{Nm}^{2}$ (case 3), and $350 \mathrm{Nm}^{2}$ (case 5) (current direction of $180^{\circ}$, wave direction of $180^{\circ}$, wave height of $3.5 \mathrm{~m}$, and wave period of $7.5 \mathrm{~s}$ )

Note that the results presented in Fig. 14 are for the initial design of the cable (see Table 3) for ease of comparison with the corresponding curvature response (Fig. 7). The results shown in Fig. 14 represent the maximum possible fatigue damage accumulated along the cable over 10 min under different environmental conditions. The most critical point is always near the WEC side, namely, all values shown in Fig. 14 originated from the third element of the cable near the WEC. Finally, if we multiply the fatigue damage readings from Fig. 14 with the probability of each wave condition as stated in Table 6 and calculate the corresponding fatigue life, a predicted fatigue life of 455 years is obtained for the cable.

This fatigue life predicted using our methodology may be considered as an upper bound on the service life for several reasons. First, a simplified model of the cable (which is an umbilical in reality but is modelled as a circular tube) was used in the analyses. The long fatigue life shows that this model must be improved in future work. Second, as described in Sect. 2.2, the present fatigue methodology is based on the first-principle design level and, consequently, does not include all the intrinsic mechanisms that lead to the fatigue degradation of the cable (such as wear, bio-corrosion, and fretting). Third, the presented results disregard the contribution from survival wave conditions and may therefore over-predict the actual fatigue life. Fourth, only regular waves were simulated in this study, and hence, the contribution to fatigue damage from single large waves under irregular waves is disregarded. However, the potential over-prediction of the fatigue life is considered to be limited since the energy content of the waves was maintained in this study (see Sect. 4.1.2 for details). Fifth, in the estimation of the fatigue life of the cable, the wind load acting on the WEC was disregarded (see Sect. 3). The accurate modelling of the wind load is a matter for future work. However, a few initial simulations were conducted based on the reference condition as defined in Sect. 4.1.2. An extreme wind load corresponding to a wind speed of $41 \mathrm{~m} / \mathrm{s}$ [46] was used together with an estimated projected area of $15 \mathrm{~m}^{2}$. No correlation between wind speed and wave height was considered; however, the purpose was simply to investigate an extreme wind load case to determine the extent to which the fatigue life of the power cable would be reduced in that case. The results showed that the cable fatigue life was reduced by approximately $10 \%$, which is a reasonable estimate for this combination of wind speed and wave height. Finally, after evaluation of the potential causes of the over-prediction of the cable's fatigue life, it was found that the findings shown in Fig. 14 can serve as a credible design reference.

\section{Conclusions}

In this study, we developed a numerical model of a WEC system and performed a global analysis of its free-hanging power cable, which has unique properties for the application of interest. A coupled simulation model was used to simulate the motion and structural responses of the WEC system, and a stress-based fatigue analysis was applied to predict the fatigue damage to the cable. The developed model and methodology were demonstrated to be useful for studying the dynamics and fatigue characteristics of the power cable.

Based on the initial design for the cable, a systems engineering approach was used together with the proposed model and methodology to investigate alternative cable 
Fig. 14 The fatigue-wave height-wave period matrix using the initial design values for the cable (see Table 3): maximum accumulated fatigue damage along the cable over $10 \mathrm{~min}$ for different wave heights and wave periods (current direction of $180^{\circ}$ and wave direction of $\left.180^{\circ}\right)$. For all wave conditions that were not simulated, the corresponding cells are marked with black dots

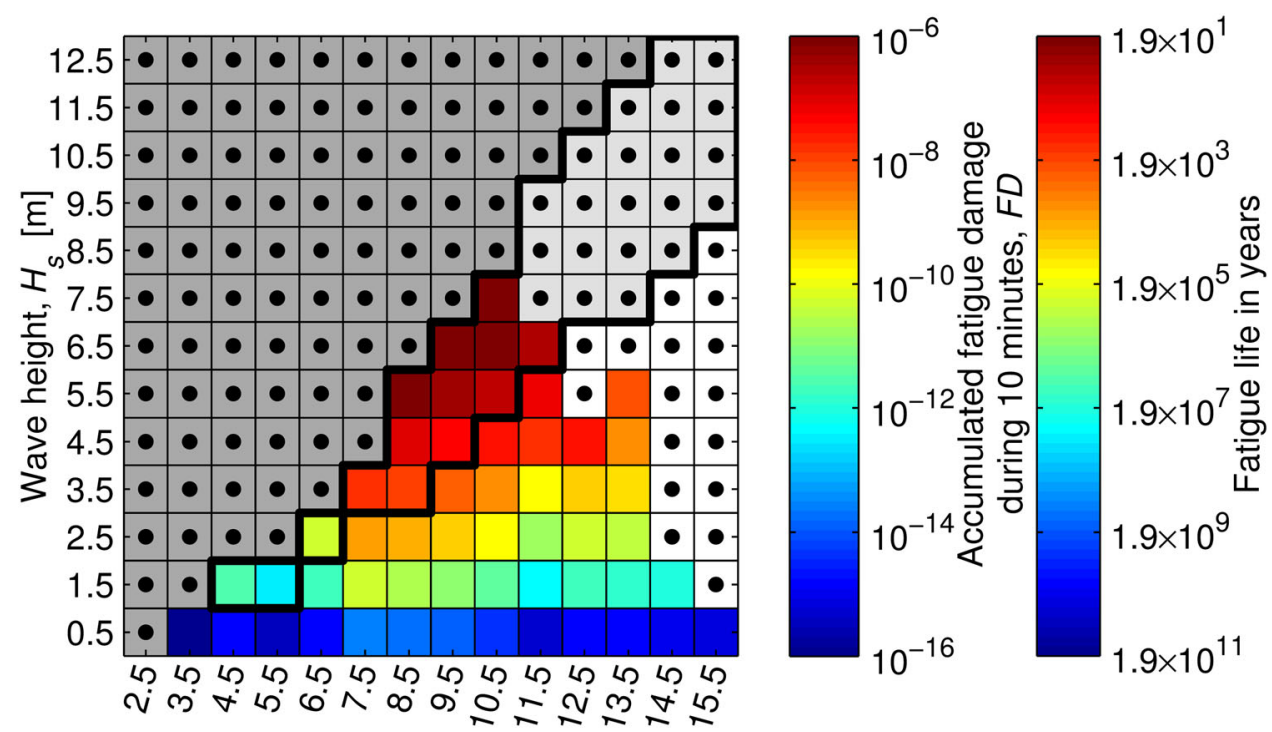

Wave period, $T_{z}[\mathrm{~s}]$ configurations that might be better suited for the WEC system addressed in this study. A parametric study was conducted in which three cable design parameters were varied. An improved cable design was identified, corresponding to a cable with a mass of $2.00 \mathrm{~kg} / \mathrm{m}$, a bending stiffness of $50 \mathrm{Nm}^{2}$, and a length of $70 \mathrm{~m}$. These properties define the cable that was found to have the least risk of physical contact between the cable and the WEC buoy as well as the longest fatigue life among the cable configurations investigated in the parametric analysis.

The methodology developed in this study enables the investigation of a cable that is relatively short and freely hanging in a WEC system. Because of its flexibility and dynamic characteristics, the studied cable is unique compared with traditional underwater power cables. Based on the extensive parametric analysis presented here with respect to environmental loads and cable design parameters, additional observations and conclusions can also be drawn that are applicable to similar dynamic cables used in WEC systems:

- Two factors influence the operational limits of the cables to be used in the WEC array system: interactions between the motion of the cable and the WEC buoy, which can result in contact between these components, and localized rippling along the cable, which can occur in certain simulated cases and ultimately leads to a shortened service life due to unforeseen fatigue.

- Large curvature responses of the cable typically occur at high wave heights and near the wave period of resonance. One exception is when the current is perpendicular to the cable (namely, at $90^{\circ}$ and $270^{\circ}$, as shown in this study); in this case, the curvature response is insensitive to the wave period and is governed by the wave height alone. Thus, to design a cable that can withstand extreme conditions, the environmental conditions considered in the model should be chosen carefully and the conjunction of environmental loadings should also be considered.

- The process of eliminating numerous design parameters in the initial phase of a structural design project can be quite difficult, especially with regard to deciding which parameters to consider. A parametric analysis was therefore adopted in this study, and this analysis was demonstrated to be highly beneficial in reducing the total number of design parameters and, consequently, in identifying the critical design parameters that contribute to the fatigue damage behaviour of the cable.

- There are several alternative methods of decreasing the curvature response of a cable where some of them are connected: increasing the cable mass, the bending stiffness or the cable length. However, all of these approaches have certain side effects that should be studied before any specific approach is adopted. Therefore, future studies will also place an emphasis on increasing the model complexity to allow these potential side effects to be properly investigated.

- A "fatigue-wave height-wave period" matrix was designed based on the wave scatter diagram at the considered test site. The cable with the initial design values was subjected to fatigue assessment using this matrix, and the results indicated a long fatigue life of 455 years. This finding demonstrates the necessity of creating a more detailed model of the cable (umbilical) as well as additional models of the intrinsic failure mechanisms that represent wear, fretting, and the influences of bio-corrosion. 
Acknowledgements The authors gratefully acknowledge the financial support provided by the Swedish Energy Agency for the project "Durability analysis of cables and mooring used in systems for harvesting of renewable ocean energy" through contract 36357-1. We also thank Filip Alm, Ph.D., and the Swedish company Waves4Power (http://www.waves4power.com/) for providing the WEC system configuration and information on future test sites. Professor Lars Bergdahl at Chalmers University of Technology and Göran Johansson, Ph.D., former at former GVA-Consultants in Gothenburg (Sweden), are also acknowledged for their advice and support.

Open Access This article is distributed under the terms of the Creative Commons Attribution 4.0 International License (http://crea tivecommons.org/licenses/by/4.0/), which permits unrestricted use, distribution, and reproduction in any medium, provided you give appropriate credit to the original author(s) and the source, provide a link to the Creative Commons license, and indicate if changes were made.

\section{References}

1. Folley M, Whittaker T (2013) Preliminary cross-validation of wave energy converter array interactions. In: Proc ASME 2013 32nd int conf ocean, offshore arct eng (OMAE2013), Nantes, France, June 9-14, 2013. American Society of Mechanical Engineers, New York, ASME Paper No. OMAE2013-10837

2. Thies PR, Johanning L, Smith GH (2012) Assessing mechanical loading regimes and fatigue life of marine power cables in marine energy applications. Proc Inst of Mech Eng. Part O J Risk and Reliab 226:18-32. doi:10.1177/1748006X11413533

3. Zhou ZR, Cardou A, Goudreau S, Fiset M (1996) Fundamental investigations of electrical conductor fretting fatigue. Tribol Int 29:221-232. doi:10.1016/0301-679X(95)00074-E

4. Nasution FP, Sævik S, Berge S (2013) Experimental investigation of fatigue performance of a $300 \mathrm{~mm}^{2}$ copper power conductor. In: Proc ASME 2013 32nd int conf ocean, offshore arct eng (OMAE2013), Nantes, France, June 9-14, 2013. American Society of Mechanical Engineers, New York, ASME Paper No. OMAE2013-11193

5. Barbeiro IdC, Yamada da Silveira LM (2013) Investigation about the effect of axial stiffness on the global response of umbilicals. In: Proc ASME 2013 32nd int conf ocean, offshore arct eng (OMAE2013), Nantes, France, June 9-14, 2013. American Society of Mechanical Engineers, New York, ASME Paper No. OMAE2013-10941

6. Brooke J (2003) Wave energy conversion, 1st edn. Elsevier Ocean Eng Ser, Oxford

7. Salter S (2008) Looking back. In: Cruz J (ed) Ocean wave energy: current status and future perspectives. Springer, Würzburg, pp 7-39

8. Lane M, McNamara JF, Gibson R, Tyrer A (1995) Bend stiffeners for flexible risers. In: 27th Annu Offshore Technol Conf, Houston, Texas, May 1-4, 1995. Paper No. OTC 7730, pp 345-353

9. Olsen E, Karlsen S, Jordal L, Hansen-Zahl KA (2012) Determination of friction within a riser umbilical. In: Proc ASME 2012 31 st int conf ocean, offshore arct eng (OMAE2012), Rio de Janeiro, Brazil, June 1-6, 2012. American Society of Mechanical Engineers, New York, ASME Paper No. OMAE2012-83089

10. Katsui T, Inoue T, Akashi M (2013) Evaluation of moving capability of crawler driven ROV considering cable tension. In: Proc ASME 2013 32nd int conf ocean, offshore arct eng (OMAE2013), Nantes, France, June 9-14, 2013. American Society of Mechanical Engineers, New York, ASME Paper No. OMAE2013-10320
11. Fortaleza E, Albuquerque D, Yamamoto M (2012) An investigation about the trajectory control during the subsea equipment installation using cable. In: Proc ASME 2012 31st int conf ocean, offshore arct eng (OMAE2012), Rio de Janeiro, Brazil, June 1-6, 2012. American Society of Mechanical Engineers, New York, ASME Paper No. OMAE2012-83798

12. Aranha JAP, Pinto MO (2001) Dynamic tension in risers and mooring lines: an algebraic approximation for harmonic excitation. Appl Ocean Res 23:63-81. doi:10.1016/S01411187(01)00008-6

13. Karlsen S (2010) Fatigue of copper conductors for dynamic subsea power cables. In: Proc ASME 2010 29th int conf ocean, offshore arct eng (OMAE2010), Shanghai, China, June 6-11, 2010. American Society of Mechanical Engineers, New York, ASME Paper No. OMAE2010-2

14. Green J, Bowen A, Fingersh LJ, Wan YH (2007) Electrical collection and transmission systems for offshore wind power. In: 2007 offshore technol conf, Houston, Texas, April 30-May 3, 2007. Paper No. OTC 19090. doi:10.4043/19090-MS

15. Buitrago J, Swearingen SFS, Ahmad S, Popelar CF (2013) Fatigue, creep and electrical performance of subsea power cable. In: Proc ASME 2013 32nd int conf ocean, offshore arct eng (OMAE2013), Nantes, France, June 9-14, 2013. American Society of Mechanical Engineers, New York, ASME Paper No. OMAE2013-10852

16. Silva D, Balena R, Lisbôa R (2012) Methodology for thermoplastic umbilical cross section analysis. In: Proc ASME 2012 31st int conf ocean, offshore arct eng (OMAE2012), Rio de Janeiro, Brazil, June 1-6, 2012. American Society of Mechanical Engineers, New York, ASME Paper No. OMAE2012-83509

17. Marta M, Mueller-Schuetze S, Ottersberg H, Isus Feu D, Johanning L, Thies PR (2015) Development of dynamic submarine MV power cable design solutions for floating offshore renewable energy applications. In: Proc Jicable'15-9th int conf insul power cables, Paris, France, June 21-25, 2015

18. Trarieux F, Lyons GJ, Patel MH (2006) Investigations with a bandwidth measure for fatigue assessment of the Foinaven dynamic umbilical including VIV. Eng Struct 28:1671-1690. doi:10.1016/j.engstruct.2006.03.014

19. Martinelli L, Lamberti A, Ruol P, Ricci P, Kirrane P, Fenton C, Johanning L (2010) Power umbilical for ocean renewable energy systems-feasibility and dynamic response analysis. In: Proc 3rd int conf ocean energy, Bilbao, Spain, October 6, 2010

20. Nasution FP, Sævik S, Berge S (2014) Experimental and finite element analysis of fatigue strength for $300 \mathrm{~mm}^{2}$ copper power. Mar Struct 39:225-254. doi:10.1016/j.marstruc.2014.07.005

21. Nasution FP, Sævik S, Gjøsteen JKØ (2014) Finite element analysis of the fatigue strength of copper power conductors exposed to tension and bending loads. Int J Fatigue 59:114-128. doi:10.1016/j.ijfatigue.2013.09.009

22. Nasution FP, Sævik S, Gjøsteen JKØ, Berge S (2013) Experimental and finite element analysis of fatigue performance of copper power conductors. Int J Fatigue 47:244-258. doi:10.1016/ j.ijfatigue.2012.09.006

23. Thies PR, Johanning L, Bashir I, Tuk T, Tuk M, Marta M, Müller-Schütze S (2016) Accelerated reliability testing of articulated cable bend restrictor for offshore wind applications. Int $\mathrm{J}$ Mar Energy 16:65-82. doi:10.1016/j.ijome.2016.05.006

24. Hansen-Zahl K, Henøen V, Baarholm R, Parsinejad F, Constantinides Y (2015) Effect of damping on VIV response in umbilicals and flexible risers. In: Proc ASME 2015 34th int conf ocean, offshore arct eng (OMAE2015), St. John's, Newfoundland, Canada, May 31-June 5, 2015. American Society of Mechanical Engineers, New York, ASME Paper No. OMAE2015-41387 
25. Liu Y, Bergdahl L (1997) Frequency-domain dynamic analysis of cables. Eng Struct 19:499-506. doi:10.1016/S01410296(96)00091-0

26. Fitzgerald J, Bergdahl L (2008) Including moorings in the assessment of a generic offshore wave energy converter: a frequency domain approach. Mar Struct 21:23-46. doi:10.1016/j. marstruc.2007.09.004

27. Chen X, Zhang J, Ma W (2001) On dynamic coupling effects between a spar and its mooring lines. Ocean Eng 28:863-887. doi:10.1016/S0029-8018(00)00026-3

28. Astrup OC (2004) DeepC - deep water coupled analysis tool. A white paper (Rev 3). Det Norske Veritas (DNV), Høvik

29. Yang S-H, Ringsberg JW, Johnson E (2014) Analysis of mooring lines for wave energy converters-a comparison of de-coupled and coupled simulation procedures. In: Proc ASME 2014 33rd int conf ocean, offshore arct eng (OMAE2014), San Francisco, CA, June 8-13, 2014. American Society of Mechanical Engineers, New York, ASME Paper No. OMAE2014-23377

30. Yang S-H, Ringsberg JW, Johnson E, Hu ZQ, Palm J (2016) A comparison of coupled and de-coupled simulation procedures for the fatigue analysis of wave energy converter mooring lines. Ocean Eng 117:332-345. doi:10.1016/j.oceaneg.2016.03.018

31. Det Norske Veritas (2013) Sesam DeepC (V4.7-07 edn). Det Norske Veritas (DNV), Høvik

32. SIMO Project Team (2012) SIMO—general description Version 4.0. Norwegian Marine Technology Research Institute (MARINTEK), Trondheim, Norway. Report No. 516412.00.01

33. Det Norske Veritas (2013) RIFLEX user's manual Version 4.0 (Rev 3). Det Norske Veritas (DNV), Høvik

34. Endo T, Morrow JD (1969) Cyclic stress-strain and fatigue behavior of representative aircraft metals. J Mater 4:159-175

35. Rychlik I (1987) A new definition of the rainflow cycle counting method. Int J Fatigue 9:119-121. doi:10.1016/01421123(87)90054-5

36. The MathWorks Inc (2013) MATLAB, R2013b edn. The MathWorks Inc, Natick

37. Waves4Power AB (2016) Homepage of Waves4power. http:// www.waves4power.com. Accessed 8 March 2017

38. Falnes J (2002) Wave-energy absorption by oscillating bodies. Ocean waves and oscillating systems: linear interactions including wave-energy extraction. Cambridge University Press, Cambridge, pp 196-224

39. OrcaFlex O (2015) Design tool for chain moorings. https://www. orcina.com/SoftwareProducts/OrcaFlex/Documentation/Help/ Content/html/Chain.htm. Accessed 8 March 2017

40. Dobson A, Frazer S (2012) Risk mitigation through the application of new power umbilical technology. In: Proc ASME 2012 31 st int conf ocean, offshore arct eng (OMAE2012), Rio de
Janeiro, Brazil, June 1-6, 2012. American Society of Mechanical Engineers, New York, ASME Paper No. OMAE2012-83878

41. Worzyk T (2009) Submarine power cables: design, installation, repair, environmental aspects. Springer, Dordrecht. doi:10.1007/ 978-3-642-01270-9

42. Det Norske Veritas (2012) RIFLEX theory manual Version 4.0. Det Norske Veritas (DNV), Høvik

43. Det Norske Veritas (2010) Recommended practice DNV-RPC205 environmental conditions and environmental loads. Det Norske Veritas (DNV), Høvik. http://diaviou.auth.gr/sites/ default/files/pegatraining/Codes-DNV-RP-C205.pdf. Accessed 8 March 2017

44. Yang S-H, Ringsberg JW, Johnson E (2015) Parametric study of the mechanical characteristics of power cables under dynamic motions. In: Proc 11th European wave tidal energy conf, Nantes, France, September 6-11, 2015. Paper No. 09D5-5

45. SIMO Project Team (2012) SIMO - theory manual Version 4.0 (Rev 1). Norwegian Marine Technology Research Institute (MARINTEK), Trondheim. Report No. 516412.00.03

46. Faltinsen OM (2002) Sea loads on ships and offshore structures. Cambridge University Press, Cambridge

47. Roussel P (1976) Numerical solution of static and dynamic equations of cables. Comput Methods Appl Mech Eng 9:65-74. doi:10.1016/0045-7825(76)90077-3

48. Aamo OM, Fossen TI (2000) Finite element modelling of mooring lines. Math Comput Simul 53:415-422. doi:10.1016/ S0378-4754(00)00235-4

49. Escalante MR, Sampaio R, Rosales MB, Ritto T (2011) A reduced order model of a $3 \mathrm{D}$ cable using proper orthogonal decomposition. In: Oscar M, Javier WS, Mario AS (eds) Mechanics Computational, pp 1143-1158

50. American Petroleum Institute (1998) API specification-17E specification for subsea umbilicals. American Petroleum Institute (API), Washington, DC

51. Chakrabarti SK (1987) Wave theories. Hydrodynamics of offshore structures. Springer, Dordrecht, pp 41-85

52. Berteaux HO (1976) Oceanographic buoy systems, classes, designs, and components-buoy system design. In: McCormick ME (ed) Buoy engineering. Wiley-Interscience, Canada, pp 199-272

53. Schlager KJ (1956) Systems engineering-key to modern development. IRE Trans Eng Manag 3:64-66. doi:10.1109/IRETEM.1956.5007383

54. Det Norske Veritas (2012) Recommended practice DNV-RPF401 electrical power cables in subsea applications. Det Norske Veritas (DNV), Høvik. https://rules.dnvgl.com/docs/pdf/DNV/ codes/docs/2012-02/RP-F401.pdf. Accessed 8 March 2017 